Autarquia Associada a Universidade de São Paulo

\title{
CARACTERIZAÇÃO CLÍNICA E EPIDEMIOLÓGICA DA NEOPLASIA PROSTÁTICA NOS ANOS DE 2012 A 2014 EM UM CENTRO DE ONCOLOGIA DO LESTE DE MINAS GERAIS
}

\author{
RENATO MARTINS ARAÚJO
}

Dissertação apresentada como parte dos requisitos para obtenção do Grau de Mestre em Ciências na Área de Tecnologia Nuclear - Aplicações

Orientadora: Prof $^{a}$. Dr ${ }^{\mathrm{a}}$ Maria Helena Bellini Marumo 
Instituto de Pesquisas Energéticas e Nucleares

Autarquia Associada a Universidade de São Paulo

\title{
CARACTERIZAÇÃO CLÍNICA E EPIDEMIOLÓGICA DA NEOPLASIA PROSTÁTICA NOS ANOS DE 2012 A 2014 EM UM CENTRO DE ONCOLOGIA DO LESTE DE MINAS GERAIS
}

\section{RENATO MARTINS ARAÚJO}

\begin{abstract}
Dissertação apresentada como parte dos requisitos para obtenção do Grau de Mestre em Ciências na Área de Tecnologia Nuclear - Aplicações

Orientadora: $\operatorname{Prof}^{\mathrm{a}}$. $\mathrm{Dr}^{\mathrm{a}}$ Maria Helena Bellini Marumo
\end{abstract}


Dedico a Fabiana, Marcela e Marina pelo amor incondicional.

Aos meus pais pelo incentivo. 


\section{AGRADECIMENTOS}

Agradeço a Deus por ter me dado força e sabedoria.

Á minha orientadora Prof ${ }^{-} \mathrm{Dr}^{\mathrm{a}}$ Maria Helena Bellini Marumo pela amizade, presteza e dedicação que me dispensou na realização desta dissertação.

Ao Instituto Metropolitano de Ensino Superior (IMES) pela oportunidade de realizar este trabalho.

As professoras Trycia Martins Salviano Alves e Analina Furtado Valadão pela ajuda e amizade.

A todos professores, diretores e funcionários do Instituto de Pesquisas Energéticas e Nucleares (IPEN) pela oportunidade de realizar este sonho.

Agradeço de maneira especial ao senhor Fernando Moreira gerente de gestão de projetos do IPEN pela dedicação à parceria IMES-IPEN.

A diretoria do Hospital Márcio Cunha e aos funcionários da Unidade de Oncologia que disponibilizaram suas instalações para a realização desta pesquisa

A todos que torceram para que este sonho se realizasse. 
"Por vezes sentimos que aquilo que fazemos não é senão uma gota de água no mar. Mas o mar seria menor se lhe faltasse uma gota". 


\title{
CARACTERIZAÇÃO CLÍNICA E EPIDEMIOLÓGICA DA NEOPLASIA PROSTÁTICA NOS ANOS DE 2012 A 2014 EM UM CENTRO DE ONCOLOGIA DO LESTE DE MINAS GERAIS
}

\author{
Renato Martins Araújo \\ RESUMO
}

O câncer de próstata ( $\mathrm{CaP}$ ) é a segunda causa mais comum de câncer em homens. De acordo com o INCA, no Brasil, em 2016, estimam-se aproximadamente 61.200 novos casos de câncer de próstata. Objetivo: Identificar as características demográficas e epidemiológicas, bem como dados do estadiamento tumoral dos pacientes com $\mathrm{CaP}$ atendidos na Unidade de Oncologia do Hospital Marcio Cunha na cidade de Ipatinga-MG nos anos de 2012, 2013 e 2014. Metodologia: Trata-se de um estudo retrospectivo e descritivo onde foram analisados 668 prontuários de pacientes, com registro do diagnóstico anatomopatológico, atendidos nos anos de 2012, 2013 e 2014, conforme lista fornecida pela instituição, com diagnóstico de CaP cadastrados com CID-10 - C 61. As variáveis analisadas foram: procedência, ano do diagnóstico, faixa etária, raça autodeclarada, fatores de risco como tabagismo, etilismo, história familiar de CaP, PSA total ao diagnóstico, tipo histológico da biópsia, score de Gleason da biópsia, tipo histológico da peça cirúrgica, score de Gleason da peça cirúrgica. Os dados foram analisados empregando-se estatística descritiva e inferencial, utilizando o software SPSS, versão 19.0. Resultados: A maior incidência de casos de CaP foram provenientes das cidades mais populosas da microrregião de saúde analisada e faixa etária mais prevalente foi entre 61 e 80 anos com prevalência em pardos e brancos e com histórico familiar de $17,2 \%$ de parentes de primeiro grau; com o pai em $37,3 \%$, o irmão em $60,8 \%$ e filho em 1,9\%. Apenas 165 (25,9\%) eram fumantes e 20,8\% etilistas. Os níveis de PSA ficaram entre $4,1 \mathrm{ng} /$ e $10 \mathrm{ng} / \mathrm{ml}(49,5 \%)$ e quanto maior a faixa etária maiores os valores do PSA. Pacientes pardos apresentaram PSA total mais elevado. Ao avaliarmos se existia relação entre os níveis de PSA total com fatores de risco como tabagismo, etilismo e histórico familiar, somente houve relação estatisticamente significativa com o etilismo. Houve concordância do score de Gleason entre biópsia e peça cirúrgica em $70 \%$, subgraduação em 18,7\% e supergraduação em 11,3\%. Comparando a idade dos pacientes com Score de Gleason, quanto maior a idade do paciente maior foi o Score de Gleason do material obtido pela biópsia via transretal Pacientes tabagistas e etilistas apresentaram Score de Gleason da peça cirúrgica mais elevados. Conclusão: A concordância entre o Score de Gleason da biópsia e o Score de Gleason da peça cirúrgica foi de $70 \%$; etilistas apresentaram PSA mais elevados; quanto maior foi a faixa etária, mais indiferenciado foi o tumor ( biópsia); pacientes tabagistas e etilistas apresentaram tumores mais indiferenciados na peça cirúrgica; este é o primeiro estudo epidemiológico de $\mathrm{CaP}$ desenvolvido na região do Vale do Aço, a caracterização sócio demográfica e as associações aqui encontradas podem contribuir com programas para desenvolver ações de controle do CaP nesta região.

Palavras-chave: Câncer da próstata. Epidemiologia. Fatores de risco. PSA (antígeno prostático específico). Score de Gleason. 


\title{
CARACTERIZAÇÃO CLÍNICA E EPIDEMIOLÓGICA DA NEOPLASIA PROSTÁTICA NOS ANOS DE 2012 A 2014 EM UM CENTRO DE ONCOLOGIA DO LESTE DE MINAS GERAIS
}

\author{
Renato Martins Araújo
}

\begin{abstract}
Prostate cancer $(\mathrm{PCa})$ is the second most common cause of cancer in men. According to INCA, in Brazil, in 2016, approximately 61,200 new cases of prostate cancer are estimated. Objective: To identify the demographic and epidemiological characteristics, as well as data on the tumor staging of patients with PCa treated at the Oncology Unit of Hospital Marcio Cunha in the city of Ipatinga-MG in the years of 2012, 2013 and 2014. Methodology: This is a retrospective and descriptive study where 668 patients' records, with a diagnosis of pathological diagnosis, were analyzed in the years 2012, 2013 and 2014 , according to the list provided by the institution, with a diagnosis of $\mathrm{PCa}$ registered with ICD-10-C 61. The analyzed variables were: origin, year of diagnosis, age group, selfreported race, risk factors such as smoking, alcoholism, family history of PCa, total PSA at diagnosis, histological type of biopsy, Gleason score of biopsy, histological type of the surgical specimen, Gleason score of the surgical specimen. Data were analyzed using descriptive and inferential statistics, using SPSS software, version 19.0. Results: The highest incidence of $\mathrm{PCa}$ cases came from the most populated cities of the analyzed health micro-region and the most prevalent age group was between 61 and 80 years old, with prevalence in brown and whites and with a family history of $17.2 \%$ of first-degree relatives degree; With father in $37.3 \%$, brother in $60.8 \%$ and son in $1.9 \%$. Only 165 $(25.9 \%)$ were smokers and $20.8 \%$ were alcoholics. PSA levels ranged from $4.1 \mathrm{ng} / \mathrm{e}$ to $10 \mathrm{ng} / \mathrm{ml}(49.5 \%)$ and the higher the age group the higher the PSA values. Brown patients had higher total PSA. When we evaluated whether there was a relationship between total PSA levels and risk factors such as smoking, alcohol consumption and family history, there was only a statistically significant relationship with alcohol consumption. There was concordance of the Gleason score between biopsy and surgical specimen in $70 \%$, subgrade in $18.7 \%$ and overdose in $11.3 \%$. Comparing the age of patients with Gleason score, the greater the patient's age, the greater the Gleason score of the material obtained by the transrectal biopsy. Smokers and alcoholists presented the highest Gleason score of the surgical specimen. Conclusion: The agreement between the Gleason score of the biopsy and the Gleason score of the surgical specimen was 70\%; Higher PSA levels; The longer the age group, the more undifferentiated was the tumor (biopsy); Smokers and alcoholics presented more undifferentiated tumors in the surgical specimen; This is the first epidemiological study of PCa developed in the Vale do Aço region, the socio-demographic characterization and the associations found here can contribute with programs to develop actions of control of $\mathrm{PCa}$ in this region.
\end{abstract}

Key words: Prostate cancer. Epidemiology. Risk factors. PSA (prostate specific antigen). Gleason score. 


\section{SUMÁRIO}

Página

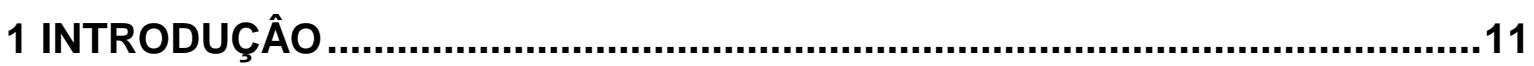

2 OBJETIVOS

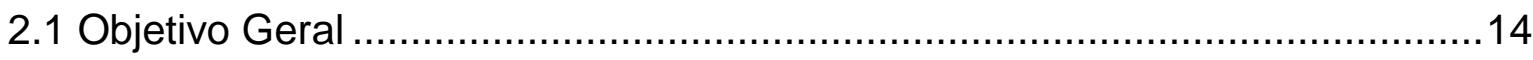

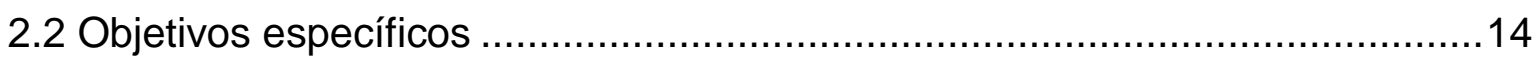

3 REVISÃO DA LITERATURA

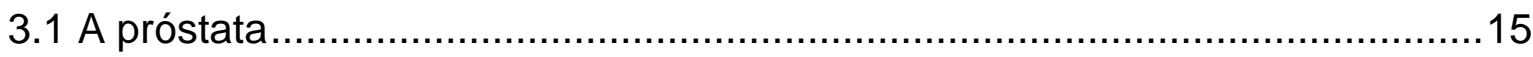

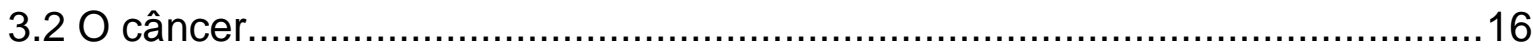

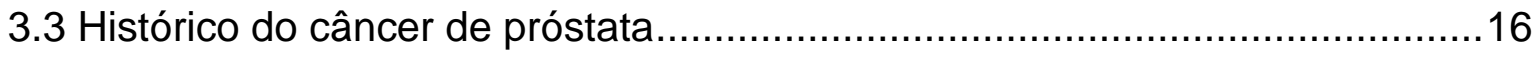

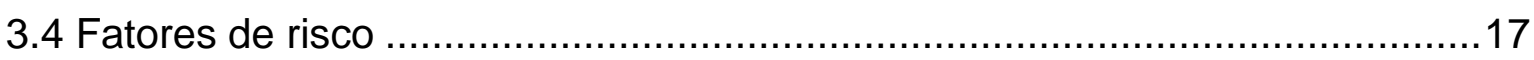

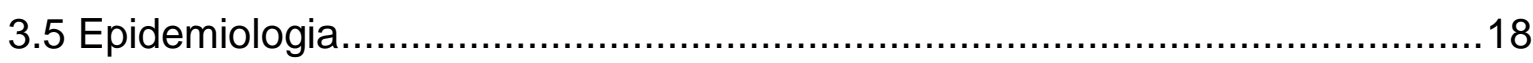

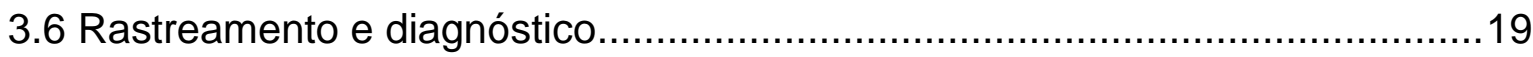

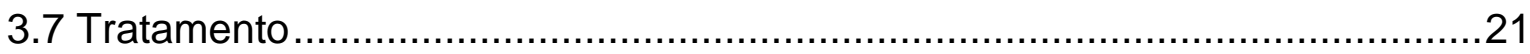

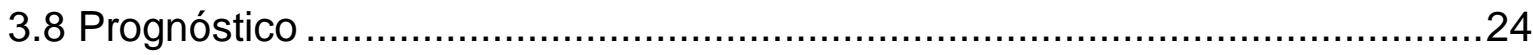

3.9 Impactos sociais e econômicos do câncer de próstata ......................................24

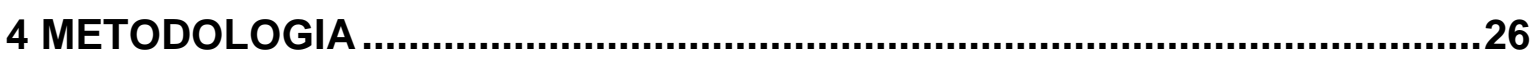

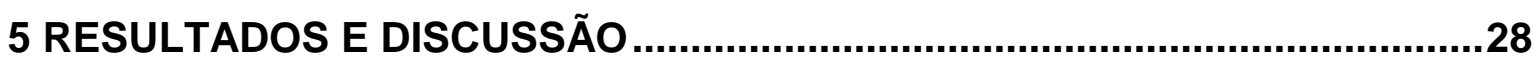

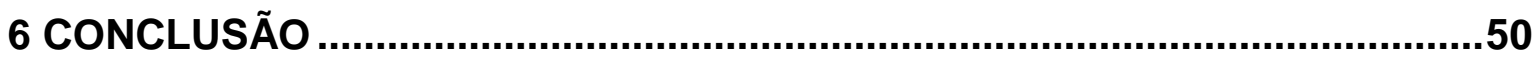

APÊNDICE A - Formulário de coleta de dados .............................................51

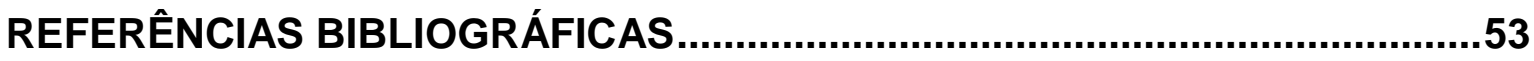




\section{LISTA DE TABELAS}

Página

TABELA 1 - Distribuição dos pacientes segundo a procedência geográfica..........28

TABELA 2 - Distribuição dos pacientes por faixa etária........................................32

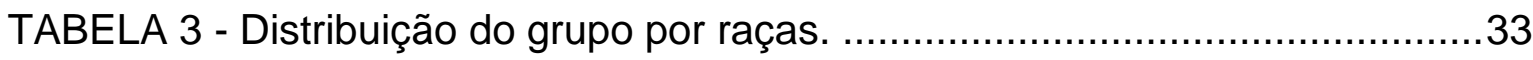

TABELA 4 - Histórico familiar relacionado ao diagnóstico de câncer de próstata.35 TABELA 5 - Frequências do etilismo e do tabagismo nos pacientes com CaP. ...36 TABELA 6 - Distribuição dos pacientes de acordo com os níveis de PSA sérico

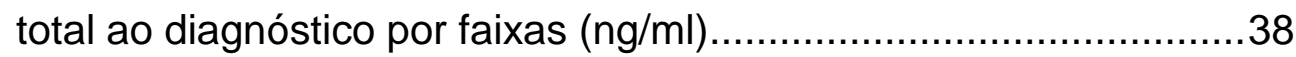

TABELA 7 - Distribuição do estadiamento patológico (Score de Gleason) do material obtido por biópsia transretal da próstata ............................39

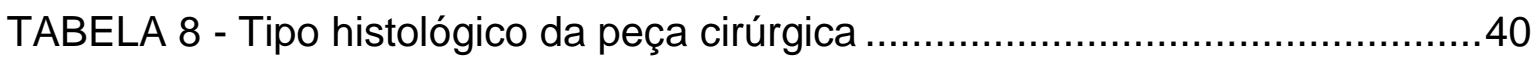

TABELA 9 - Distribuição do estadiamento patológico (Score de Gleason) da peça cirúrgica

TABELA 10 - Nível de concordância do Score de Gleason entre material obtido na biópsia e peça cirúrgica ........................................................... 40

TABELA 11 - Levantamento da situação do paciente...........................................42

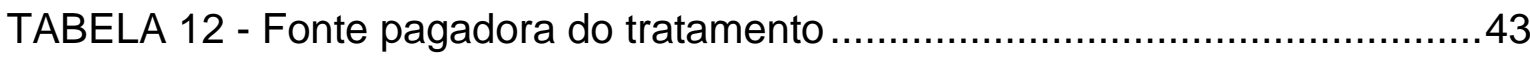

TABELA 13 - Níveis de PSA sérico dos pacientes relacionados a faixa etária .....43

TABELA 14 - Níveis de PSA sérico dos pacientes relacionados à raça ................44

TABELA 15 - Comparação entre PSA total ao diagnóstico e fatores de risco .......45

TABELA 16 - Associação entre faixa etária e estadiamento de Gleason da

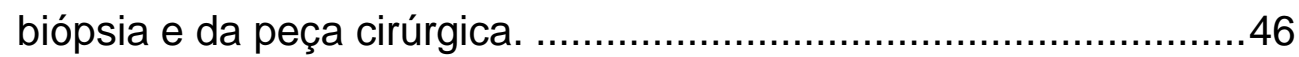

TABELA 17 - Associação entre raça e estadiamento de Gleason da biópsia .......47

TABELA 18 - Associação entre raça e estadiamento de Gleason da peça cirúrgica

TABELA 19 - Comparação entre Fatores de Risco e Score de Gleason da biópsia e análise anatomopatológica da peça cirúrgica 


\section{LISTA DE FIGURAS}

FIGURA 1 - Mapa do Estado de Minas Gerais ............................................................. 30

FIGURA 2 - Mapa da Microrregião de Coronel Fabriciano e Timóteo ............................... 30

FIGURA 3 - Mapa da Microrregião de Ipatinga............................................................. 31

FIGURA 4 - Distribuição anual dos pacientes com Câncer de Próstata............................ 32

FIGURA 5 - Comparação entre valores do Score de Gleason da biópsia e da peça

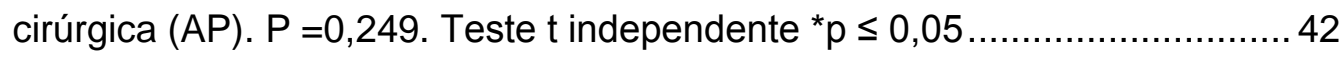




\section{LISTA DE ABREVIATURAS}

$\begin{array}{ll}\text { AJCC } & \text { Americam Joint Committee on Cancer } \\ \text { CA } & \text { Câncer } \\ \text { CaP } & \text { Câncer de Próstata } \\ \text { DNA } & \text { Ácido Desoxirribonucleico } \\ \text { FSFX } & \text { Fundação São Francisco Xavier } \\ \text { IBGE } & \text { Instituto Brasileiro de Geografia e Estatística } \\ \text { INCA } & \text { Instituto Nacional de Câncer } \\ \text { OMS } & \text { Organização Mundial da Saúde } \\ \text { PSA } & \text { Antígeno Prostático Específico } \\ \text { PSAD } & \text { Densidade do PSA } \\ \text { RM } & \text { Ressonância Magnética } \\ \text { SUS } & \text { Sistema Único de Saúde } \\ \text { SBU } & \text { Sociedade Brasileira de Urologia } \\ \text { TC } & \text { Tomografia Computadorizada } \\ \text { USTR } & \text { Ultrassonografia Transretal } \\ \text { USIMINAS } & \text { Usina Siderúrgica de Minas Gerais } \\ \text { UNILESTE-MG Centro Universitário do Leste de Minas Gerais } \\ \text { ZC } & \text { Zona Central } \\ \text { ZP } & \text { Zona Periférica } \\ \text { ZT } & \text { Zona Transicional }\end{array}$




\section{INTRODUÇÂO}

O Câncer de Próstata (CaP) representa 9,7\% das neoplasias malignas (sendo 15,3\%, em países desenvolvidos e 4,3\%, em países em desenvolvimento). É a mais prevalente e a segunda causa de morte em homens adultos segundo o Instituto Nacional do Câncer (INCA, 2014a).

A idade é um fator de risco importante para o $\mathrm{CaP}$, uma vez que, tanto a incidência, como a mortalidade aumentam, significativamente, após os 50 anos. Cerca de três quartos dos casos no mundo ocorrem nos homens a partir dos 65 anos. É, por isso, considerado o câncer da terceira idade (INCA, 2014b; Parkin, Bray; Devesa, 2001; Srougi et al., 2008).

No Brasil, o $\mathrm{CaP}$ é o segundo mais comum entre os homens, atrás apenas do câncer de pele não-melanoma.

É o sexto tipo mais comum no mundo, representando cerca de $10 \%$ do total de cânceres. Sua taxa de incidência é cerca de seis vezes maior nos países desenvolvidos (INCA, 2014b).

A estimativa do Instituto Nacional de Câncer (INCA) para o biênio 2016 e 2017 é de 61.200 novos casos e, 13.772 óbitos. Em Minas Gerais, essa estimativa é de 5.920 novos casos por 100 mil habitantes (INCA, 2016a). Em Belo Horizonte, capital do estado, são esperados 880 novos casos para o biênio citado.

Nos estágios iniciais, esta neoplasia, raramente produz sintomas. Entretanto, nos estágios avançados o paciente se queixa de dificuldade para urinar, jato urinário fraco e sensação de não esvaziamento completo da bexiga (Gonçalves; Padovani; Pompin, 2008).

Quando a doença é detectada precocemente, por exames clínicos e laboratoriais de rotina como, por exemplo, o toque retal e a dosagem do PSA, a patologia é curável em $80 \%$ dos casos. Entretanto, o diagnóstico da doença, muitas vezes, acontece quando o câncer já se disseminou para outros órgãos, o que dificulta seu tratamento (El Barouki, 2012).

Segundo Rodrigues e Sales (2013) a etiologia do CaP é indeterminada, mas sabe-se, entretanto, que alguns fatores influenciam seu desenvolvimento. 
São vários os fatores postulados para a sua promoção e início, sendo a idade um fator de risco tanto para a incidência, quanto para a mortalidade. Outro fator de risco relevante é o histórico familiar. Verificou-se um aumento de 1,5 vezes do risco da doença quando um parente de primeiro grau é acometido pelo câncer e 5 vezes quando dois ou mais foram afetados. Nestas situações, o tumor aparece de forma precoce, em alguns casos até em idades inferiores a 50 anos (Dantas et al., 2009; Ribeiro et al., 2013).

A propedêutica para investigação de $\mathrm{CaP}$ inclui a dosagem do Antígeno Prostático Específico (PSA) sérico e a biópsia guiada por ultrassonografia transretal (USTR) (Hernandez et al., 2013).

O PSA é o marcador tumoral mais utilizado no rastreio da neoplasia prostática, e possui impacto significativo nos quesitos morbidade e mortalidade. Atualmente, são considerados alterados os valores de PSA que estão acima de $2,5 \mathrm{ng} / \mathrm{ml}$. É válido ressaltar que o exame possui alta sensibilidade e baixa especificidade, pois outras causas podem elevar os valores do antígeno, como prostatite e hiperplasia prostática benigna, além da neoplasia prostática (Castro et al., 2011).

O PSA, isoladamente, não tem valor diagnóstico sendo que, $80 \%$ dos casos diagnosticados, e confirmados posteriormente, pelo anatomopatológico, quando se associa o toque retal (SBU, 2006).

No exame anatomopatológico da biópsia, se obtém o Score de Gleason, sendo este, um dos critérios mais importantes para realizar o prognóstico da doença e com isso, a escolha da terapia mais adequada. Quanto mais indiferenciado o tumor, mais agressivo é o seu comportamento. No sistema de Gleason os tumores são classificados de acordo com a diferenciação celular, sendo o Score final ou combinado, resultante da soma dos graus do padrão primário (predominante) e secundário (segundo grau histológico mais comum) (Kryvenko; Epstein, 2016).

Além dos exames já citados, a ressonância magnética $(R M)$ e a tomografia computadorizada (TC) também podem ser utilizados na abordagem propedêutica e diagnóstica do câncer de próstata, no entanto, possuem acurácia limitada se comparados a biópsia (Lima et al., 2013). 
O estadiamento do tumor, classificação histológica, preferência e acessibilidade do paciente são fatores que determinam a escolha terapêutica (Martins et al., 2000).

O objetivo desse estudo foi analisar clínica e epidemiologicamente os pacientes diagnosticados com $\mathrm{CaP}$, atendidos na Unidade de Oncologia do Hospital Márcio Cunha de Ipatinga, Minas Gerais, entre janeiro de 2012 a dezembro de 2014.

A realização deste projeto justifica-se pela ausência de dados epidemiológicos do $\mathrm{CaP}$ na região do Vale do Aço, onde existe um importante centro de tratamento especializado em oncologia. 


\section{OBJETIVOS}

\subsection{Objetivo Geral}

Identificar as características demográficas e epidemiológicas, bem como dados do estadiamento tumoral dos pacientes com câncer de próstata atendidos na Unidade de Oncologia do Hospital Marcio Cunha na cidade de Ipatinga-MG, nos anos de 2012, 2013 e 2014.

\subsection{Objetivos específicos}

- Caracterizar a população alvo do estudo quanto à faixa etária, raça (autorreferida);

- Avaliar fatores de risco relacionados com câncer da próstata como etilismo, tabagismo e história familiar;

- Descrever aspectos do diagnóstico da neoplasia como PSA total, Score de Gleason (da biópsia e da peça cirúrgica);

- Comparar fatores de risco com PSA total no diagnóstico;

- Comparar fatores de risco com Score de Gleason da biópsia e da peça cirúrgica;

- Correlacionar PSA total e idade;

- Correlacionar faixa etária com Score de Gleason da biópsia e da peça cirúrgica;

- Correlacionar raça com Score de Gleason da biópsia e da peça cirúrgica;

- Comparar Score de Gleason da biópsia e da peça cirúrgica. 


\section{REVISÃO DA LITERATURA}

\subsection{A próstata}

A próstata é uma glândula exócrina que compõe o sistema reprodutor dos indivíduos do sexo masculino. Esta glândula apresenta como função sintetizar e secretar um fluído incolor que se junta com componentes provenientes da vesícula seminal e do testículo para originar o sêmen (McAninch; Lue, 2014, Rous, 2010).

Anatomicamente, nos humanos, a próstata localiza-se abaixo da bexiga, na frente do reto e envolve a uretra, apresentando tamanho aproximado de uma noz e peso em torno de 20 gramas (McAninch; Lue, 2014).

No interior da próstata, a uretra oriunda da bexiga recebe o nome de uretra prostática e associa-se com os dois ductos ejaculatórios. Esta glândula também possui alguns músculos lisos que auxiliam na eliminação do sêmen durante a ejaculação (McAninch; Lue, 2014).

Mais comumente na patologia, a próstata é classificada em quatro zonas glandulares que diferem entre si:

- Zona periférica (ZP): corresponde a aproximadamente $70 \%$ da próstata normal em indivíduos jovens. É nesta região que se iniciam $70 \%$ dos cânceres de próstata.

- Zona central (ZC): corresponde a aproximadamente $20 \%$ da próstata normal, compreendendo os ductos ejaculatórios. As neoplasias nessa região somam cerca de $25 \%$ da totalidade dos cânceres de próstata.

- Zona transicional (ZT): esta região compreende em torno de $5 \%$ do volume prostático. Esta região quase nunca está relacionada com câncer de próstata.

- Zona fibro-muscular anterior (ou estroma): esta zona corresponde a cerca de $5 \%$ da totalidade da próstata e normalmente não possuiu elementos glandulares, sendo formada apenas por músculo e tecido fibroso (McAninch; Lue, 2014).

Já na anatomia, a denominação mais utilizada é lobos: 
- Lobo anterior (ou istmo): compreende aproximadamente uma porção da ZT.

- Lobo posterior: compreende quase que toda a ZP.

- Lobos laterais: abrange todas as zonas.

- Lobo mediano (ou lobo médio): compreende cerca de uma porção da ZC.

Dentre as patologias mais frequentes na próstata, encontra-se o câncer de próstata, hiperplasia prostática benigna e prostatite (Rous, 2010).

\subsection{0 câncer}

Conforme definição do INCA (2016b), câncer é um grupo de patologias que se caracterizam pelo crescimento desordenado e exagerado de células que penetram tecidos e órgãos e têm a capacidade de se disseminar para outros locais do corpo.

O câncer é considerado uma doença fundamentalmente genética que se desenvolve pelo acúmulo de mutações que surgem como consequência de mudanças patológicas nas informações contidas no ácido desoxirribonucleico (DNA). Essas mutações podem ser causadas por agentes mutagênicos, que incluem radiação ionizante, químicos carcinogênicos ou ainda podem ocorrer espontaneamente como resultado de alterações nos processos de replicação e reparo do DNA. Essas mutações conferem as células mutantes uma vantagem competitiva em relação às células normais, proporcionando-lhes aumento da proliferação e da sobrevivência celular (Alberts et al., 2010).

A próstata é uma glândula tipicamente masculina, responsável por produzir e secretar o líquido prostático. Entre os vários tipos de câncer, o que acomete este órgão, é definido como crescimento excessivo da mesma, que provoca um decréscimo da intensidade e do calibre do jato urinário durante $\mathrm{o}$ ato miccional (Rous, 2010).

\subsection{Histórico do câncer de próstata}

O adenocarcinoma representa cerca de $98 \%$ dos canceres de próstata. Sendo que, mais de $90 \%$ dos pacientes com adenocarcinoma de próstata localmente avançado apresentam-se com manifestações de obstrução infravesical, sendo comum o aparecimento súbito dessa obstrução em um paciente com padrão miccional recentemente satisfatório. Também evidencia-se 
hematúria macroscópica, geralmente quando apresenta infiltração do trígono pelo tumor. Na hiperplasia benigna, os sintomas obstrutivos apresentam evolução mais lenta (Srougi et al., 2008).

De acordo com o Ministério da Saúde a história natural do CaP é incompreensível, variando desde tumores bastante agressivos até aqueles de evolução lenta, que podem não despertar sintomas ou levar a morte. Muitos homens acometidos com o câncer de próstata morrem com a doença sem saber do diagnóstico vitimado por outras patologias. Percebe-se que não é uma doença única, mas um conjunto de evoluções clínico-patológicas (Brasil, 2010).

O câncer de próstata possui três formas distintas de apresentação, sendo estas: tumor latente, tumor metastático e tumor indolente. $O$ tumor latente costuma ser encontrado nas necropsias, em uma incidência de $80 \%$ dos casos em homens com mais de 80 anos. O tipo metastático, que representa $5 \%$ da totalidade dos pacientes com CA prostático, constitui o tumor que não se restringe apenas ao sítio primário (próstata) e apresenta invasão a tecidos adjacentes ou mesmo à distância. A terceira classificação, denominada indolente, refere-se ao tumor que embora diagnosticado clinicamente, não representa perigo ou letalidade, podendo também ser chamado de "mínimo" ou "insignificante" (Ortiz, 2013).

\subsection{Fatores de risco}

Principal fator de risco associado ao câncer de próstata é a idade igual ou superior a 50 anos. Por volta de $62 \%$ dos casos ocorrem em homens maiores de 65 anos e com a crescente expectativa de vida espera-se ampliação do número de novos casos (Damião et al., 2015).

De acordo com alguns estudos, fatores como etnia/raça foram considerados fatores de risco para câncer de próstata, pois é duas vezes mais prevalente em negros em comparação com brancos e é mais incidente em homens naturais dos Estados Unidos, Jamaica e Caribe, que possuem linhagem africana, valores que correspondem a 10 a 40 vezes mais incidentes em afroamericanos que em asiáticos (Damião et al., 2015; Jurado et al., 2013).

Outro fator de risco relevante é o histórico familiar, pois, verificou-se um risco relativo elevado de $\mathrm{CaP}$ em parentes de primeiro grau de pacientes que desenvolveram CaP antes dos 50 anos (Walsh; Retik; Stamey, 1997). 
O hábito alimentar do paciente também é mencionado como fator de risco, sendo que, dietas ricas em gorduras saturadas e carente em fibras aumentam essas chances, como o caso dos ácidos linoleico ou hidrocarbonetos decorrentes do processo de preparo de carne vermelha (Ribeiro et al., 2013). A vitamina $D$ age direta ou indiretamente em mais de 200 genes relacionados ao controle do ciclo celular, diferenciação, apoptose e angiogênese, estimulando ou interrompendo a multiplicação de células normais ou neoplásicas, e a hipovitaminose $\mathrm{D}$ é considerada como um fator de risco devido ao calcitriol, forma ativa desta vitamina, capaz de deter a evolução do câncer de próstata por impedir a multiplicação de células fenotipicamente malignas (Boneti; Fagundes, 2013).

\subsection{Epidemiologia}

O câncer de próstata é considerado o segundo tipo mais incidente no mundo entre homens, valor que corresponde a $10 \%$ do total dos tumores malignos, representando a segunda maior causa de morte por câncer no Brasil. É seis vezes mais incidente em países desenvolvidos em relação aos em desenvolvimento, os valores de incidência, por região, correspondem a 95,63/100 mil no sul, $67,59 / 100$ mil no centro-oeste, $62,36 / 100$ mil no sudeste, $51,84 / 100$ mil no nordeste e 29,50/100 mil no norte (INCA, 2014c).

De acordo com o Instituto Nacional do Câncer (INCA, 2014d) o Brasil registrou uma taxa de mortalidade, ajustada para a população do ano de 2010 por câncer de próstata de 16,46 para 100 mil habitantes. Foram 13.354 óbitos registrados no país decorrente dessa doença no ano de 2012, o que equivale a $13,1 \%$ das mortes devido ao câncer no sexo masculino. A taxa de mortalidade mundial para o mesmo período foi de 13,65 para 100 mil habitantes (INCA, 2014d).

Para o ano de 2016 o número estimado de novos casos de câncer de próstata é de 61.200. Em Minas Gerais esses valores correspondem a 5.920 e na capital do estado são esperados 880 novos casos para o ano de 2016. Segundo a distribuição por regiões, são estimados para a região sudeste (25.800), nordeste (14.290) e sul (13.590) de novos casos. Apenas no estado de Minas Gerais, na última década, foi registrada uma taxa de mortalidade bruta por câncer de próstata de 11,77 casos por 100 mil habitantes e estima-se uma incidência de 5.920 casos para cada 100 mil habitantes (INCA, 2016c). 


\subsection{Rastreamento e diagnóstico}

O Ministério da Saúde, baseado em evidências científicas disponíveis atualmente e em recomendações da Organização Mundial da Saúde (OMS), opta por não recomendar ações de rastreio para o $\mathrm{CaP}$. Os riscos e benefícios do rastreio devem ser discutidos pelos médicos com os pacientes que espontaneamente procurarem o serviço de saúde (Brasil, 2010).

A propedêutica para investigação do $\mathrm{CaP}$ inclui a dosagem do PSA e a biópsia guiada por ultrassonografia transretal (USTR) (Jurado et al., 2013).

Sabe-se que o câncer da próstata possui natureza silenciosa, e que muitas vezes o perfil histológico da doença impera em detrimento aos sintomas. Ainda assim, a sintomatologia mais comum nos indivíduos engloba jato urinário fraco, disúria, noctúria, dor à miç̧ão, polaciúria, ardência miccional, retenção urinária, dificuldade para iniciar a micção, hematúria, perda de peso, adinamia, e dor óssea em casos mais avançados da doença (Ribeiro et al., 2013).

O toque retal faz parte do exame físico do paciente e também é uma medida empregada no rastreio da neoplasia, no entanto, não é uma medida plenamente eficaz, uma vez que é difícil palpar alterações na próstata nos estádios iniciais da doença, e mesmo que sejam percebidas alterações mediante a palpação, não é possível afirmar se trata de uma alteração benigna ou maligna (Castro et al., 2011).

O PSA é o marcador tumoral mais utilizado no rastreio da neoplasia prostática, e possui impacto significativo nos quesitos morbidade e mortalidade. Atualmente, são considerados alterados os valores de PSA que estão acima de $2,5 \mathrm{ng} / \mathrm{ml}$. É válido ressaltar que o exame possui alta sensibilidade e baixa especificidade, sendo assim, outras causas podem elevar os valores do antígeno, como prostatite e hiperplasia prostática benigna, além da neoplasia prostática (Castro et al., 2011).

O uso da dosagem de PSA para diagnóstico de câncer de próstata não é recomendado isoladamente. Na literatura, a associação do PSA com o Toque Retal mostra-se promissora, já que correspondem a $80 \%$ dos casos diagnosticados confirmados posteriormente pelo anatomopatológico em casos de prostatectomia radical (Nardi et al., 2014).

O estudo realizado por Castro et al. (2011) evidenciou que o aumento dos valores de PSA e a correlação com a neoplasia instalada era maior nos 
indivíduos de idade mais elevada, sobretudo aqueles com mais de 69 anos, ou seja, quanto mais velhos os pacientes, menor a chance de ocorrer falso negativo. Além disso, percebeu que a maioria dos homens com valores acima de $8,9 \mathrm{ng} / \mathrm{ml}$ tinham resultado positivo para $\mathrm{CaP}$. Nesse mesmo estudo, observou-se que utilizando a técnica de Densidade do PSA (PSAD), que consiste em dividir o valor do PSA total pelo volume prostático, a acurácia do exame era maior, reduzindo significativamente o número de biópsias realizadas sem necessidade (Castro et al., 2011).

A biópsia por USTR é um bom método empregado na prática para diagnosticar câncer de próstata. Através dela, com o emprego de boa técnica na sua execução é possível estabelecer o diagnóstico histológico do câncer (Jurado et al., 2013).

Através do exame anatomopatológico do material obtido pela biópsia, é possível determinar o Score de Gleason, sendo este, um dos critérios mais importantes para estabelecer o estadiamento, o prognóstico da doença e também auxilia na escolha da terapia mais adequada. É importante ressaltar, que quanto mais indiferenciado o tumor, mais agressivo é o seu comportamento. O Score de Gleason pode ser classificado como bem diferenciado (Gleason 2-4), moderadamente diferenciado (Gleason 5-6) e indiferenciado (8-10). O somatório de Gleason 7 algumas vezes tem sido agrupado junto com tumores moderadamente diferenciados e em outras ocasiões com tumores pouco diferenciados, indicando pior prognóstico (McAninc; Lue, 2014; Moreira et al., 2012).

Em um trabalho de referência para estudos em câncer de próstata D'Amico et al. (1999) estratificaram os homens com tumor de próstata mediante um somatório de três fatores, como forma de predizer o prognóstico após tratamento radioterápico, procedimento esse que também é útil naqueles casos encaminhados para cirurgia. Homens com tumores de baixo risco apresentam Score de Gleason < 7, PSA abaixo de $10 \mathrm{ng} / \mathrm{dl}$ e tumor não palpável ao exame digital da próstata. Homens com tumores de risco intermediário apresentam Score de Gleason = 7, PSA entre 10 e $20 \mathrm{ng} / \mathrm{dl}$ e apenas um pequeno nódulo que não infiltra a parede retal ao exame digital. Homens com tumores de alto risco apresentam Score de Gleason > 7, múltiplos nódulos (ou endurecimento difuso da próstata) ao exame digital e PSA maior que $20 \mathrm{ng} / \mathrm{dl}$. Considerando esses três 
grupos, os homens apresentariam cerca de $80 \%$, 62\% e 35\% de chances de sobrevida de cinco anos, livres de recorrência bioquímica, se incluídos nos grupos de baixo risco, de risco intermediário ou de alto risco, respectivamente, o que auxiliaria na programação do tratamento (D’Amico et al., 1999).

Em relação aos métodos por imagem, a ultrassonografia suprapúbica não deve ser utilizada rotineiramente para a confirmação diagnóstica do câncer devido ao número elevado de falsos-positivos, por não se diferenciar a hipertrofia prostática benigna do câncer da próstata. A ultrassonografia transretal mostrou baixa sensibilidade em detectar cânceres invasivos sendo responsável por um subestadiamento. A indicação da Ressonância Magnética encontra-se reservada para alguns casos, já que esse é um tipo de exame dispendioso e pouco acessível em várias localidades. Representa uma alternativa para pacientes com resultado de biópsia guiada por ultrassonografia transretal prévia negativa e com níveis elevados de PSA e que exigem um acompanhamento direto e para estadiamento do tumor. O momento ideal para realização da biópsia necessita de uma avaliação individual dos casos, pois, trata-se de um exame invasivo, que pode apresentar complicações. Os fatores de risco do câncer de próstata devem ser sempre observados ao se solicitar esse tipo de exame. A primeira biópsia será sempre recomendada diante de toque retal com resultado alterado independente dos valores do PSA (Nardi et al., 2014).

O diagnóstico definitivo é estabelecido apenas pela biópsia. Sendo que, a probabilidade de diagnóstico do câncer da próstata é menor a partir da segunda biópsia, e o pedido de novos exames deve seguir critérios reservados, baseados na clínica individual dos pacientes (Nardi et al., 2014).

\subsection{Tratamento}

Antes de definir o tratamento de escolha para o paciente com câncer de próstata é necessário que se faça o estadiamento tumoral. Para isso utiliza-se a padronização do American Joint Committee on Cancer (AJCC, 2016) que estabelece o seguinte estadiamento para o câncer da próstata:

- Estadiamento $T$ refere-se à extensão tecidual do tumor, abrangendo os seguintes casos:

- Tx: tumor primário, que não pode ser definido.

- To: tumor primário, que não é evidente. 
- T1: tumor clinicamente não aparente em exames tanto de imagem quanto físicos.

- T1a: tumor achado incidentalmente em menos de $5 \%$ da peça de ressecção prostática.

- T1b: tumor achado incidentalmente em mais de $5 \%$ da peça de ressecção prostática.

- T1c: tumor identificado em biopsia prostática por aumento de PSA.

- T2: tumor confinado à próstata.

- T2a: tumor que invade metade ou menos de um lobo prostático.

- T2b: tumor que invade mais da metade de um lobo, mas não os dois lobos.

- T2c: tumor que invade ambos os lobos prostáticos.

- T3: tumor que se estende além da cápsula prostática.

- T3a: tumor com extensão extracapsular unilateral ou bilateral.

- T3b: tumor que invade vesículas seminais.

- T4: tumor fixo ou com invasão de tecidos adjacentes, como parede pélvica, esfíncter estriado, reto e bexiga.

- Estadiamento $N$ refere-se ao estado dos linfonodos regionais, assim discriminados:

- Nx: impossibilidade de determinação dos linfonodos regionais

- N0: ausência de acometimento linfonodal regional

- N1: presença de acometimento linfonodal regional

- Estadiamento M refere-se à presença ou ausência de metástases a distância, conforme descrito abaixo:

- M0: ausência de metástase a distância

- M1: presença de metástase a distância

- M1a: presença de metástase em linfonodos não regionais

- M1b: presença de metástases ósseas

- M1c: presença de metástases em outros locais com ou sem metástases ósseas.

A escolha do tratamento depende do estadiamento final do câncer da próstata, podendo este ser localizado, localmente avançado ou avançado.

Ao realizar a escolha terapêutica da neoplasia, deve-se ter em mente que não há consenso no que tange a melhor alternativa. Dentre as opções estão 
a radioterapia externa, braquiterapia, tratamento por supressão androgênica, prostatectomia radical e vigilância ativa (Westover et al., 2012).

Deve-se levar em consideração o estadiamento do tumor, classificação histológica, preferência e acessibilidade do paciente ao realizar a escolha terapêutica (Martin et al., 2012).

A realização da prostatectomia radical, um procedimento cirúrgico curativo, está bem indicada quando o tumor está confinado na próstata. Este procedimento consiste na retirada total da glândula e na linfadenectomia locoregional (Rapiti et al., 2013).

A opção radioterápica oferece duas formas distintas, uma em que a radiação pode vir de uma fonte externa (radioterapia externa), a outra proveniente de uma fonte localizada próxima ao tumor, inserida dentro da glândula (braquiterapia). A radioterapia possui indicação similar à do procedimento cirúrgico, porém, tem demonstrado menores efeitos colaterais ao término do tratamento, com menores taxas de ocorrência de disfunção sexual e sintomas genitourinários (Novaes; Motta; Ludgren, 2013).

No caso de câncer metastático, o tratamento por supressão androgênica, também conhecido como hormonioterapia é o mais indicado. Nesta terapia são empregados vários medicamentos à base de hormônios (estrógenos, análogos da LHRH e antiandrógenos), que impedem a produção de testosterona ou bloqueiam as suas ações na próstata. De forma análoga, também pode ser realizada a castração (orquiectomia), que consiste na retirada cirúrgica dos testículos, também utilizada como método supressor hormonal, pois elimina os órgãos que produzem o hormônio masculino, o principal responsável pelo crescimento do tumor (Jurado et al., 2013).

A vigilância ativa consiste na adoção de uma conduta expectante, que pode ser definitiva ou não, retardando a opção curativa para um segundo momento se houver critérios de progressão da doença. Essa é uma opção bem indicada para os tumores ditos indolentes, de modo a não expor o paciente aos riscos e complicações dos demais tratamentos, visto que o tumor pode não apresentar comportamento nocivo. $O$ protocolo de seguimento da vigilância ativa exige a dosagem de PSA e toque retal semestralmente. Após um ano, a realização de uma biópsia, e a partir daí, a solicitação de uma nova biópsia a cada três anos. O emprego deste método será provavelmente mais realizado, 
quando existirem melhores marcadores moleculares, que traduzirão com melhor eficácia o prognóstico da doença (Ortiz, 2013).

É valido ressaltar que, independente da escolha terapêutica, após o tratamento adotado, o paciente deverá continuar o seguimento propedêutico, realizando acompanhamento adequado, com novas dosagens de PSA, para acompanhar a possibilidade de recidiva do tumor (Novaes; Motta; Ludgren, 2013).

\subsection{Prognóstico}

Foram elencados alguns fatores essenciais que determinam 0 prognóstico de um paciente com $\mathrm{CaP}$, dentre eles estão: o estadiamento, o grau histológico e o PSA. Existem ainda fatores adicionais que podem ser avaliados para prognóstico da doença como exames histológicos mais detalhados e o volume tumoral, mas que não será dada ênfase por não serem comumente utilizados (SBU, 2006).

O estadiamento, de acordo com a extensão anatômica do tumor, é considerado o mais importante dentre eles. O valor do PSA fornece informações importantes para determinar o prognóstico, entretanto não é um bom marcador isolado. Se o valor do PSA Total for menor que $4 \mathrm{ng} / \mathrm{ml}$ existe uma probabilidade de $80 \%$ da doença estar restrita ao órgão, se menor que $10 \mathrm{ng} / \mathrm{ml}$ há baixo risco de metástase a distância, maior que $10 \mathrm{ng} / \mathrm{ml}$ a chance de extensão extracapsular é maior que $60 \%$, se maior que $50 \mathrm{ng} / \mathrm{ml}$ o risco é alto de doença metastática à distância (SBU, 2006).

A avaliação do Score de Gleason igual ou maior a 7 considera o tumor biologicamente agressivo, se o Score entre 5 e 6 a agressividade é considerada intermediaria, e entre 2 e 4 a agressividade é menor (SBU, 2006).

\subsection{Impactos sociais e econômicos do câncer de próstata}

No ano de 2009, o Ministério da Saúde lançou a Política Nacional de Atenção Integral à Saúde do Homem visando corrigir vários problemas identificados ao longo dos 20 anos de implantação do Sistema Único de Saúde (SUS) na atenção em saúde ao gênero masculino. Foi evidenciado que essa população é mais susceptível a enfermidades graves e crônicas e que seu acesso ao sistema de saúde ocorria em grande parte dos casos por meio da atenção 
secundária. Além dos agravos decorrentes da busca tardia da assistência médica, essa atitude ocasiona onerosos gastos ao sistema de saúde (Brasil, 2009a).

O modelo patriarcal e profundo valor sócio cultural ainda arraigado contribuem para a manutenção na sociedade de pensamentos errôneos a respeito da doença e do padecimento por parte do sexo masculino. O homem, tido como a figura principal do seio familiar e provedor maior, relega ao segundo plano, cuidados básicos referentes à sua saúde. Devido a isso, há uma baixa demanda na atenção primária pelas medidas de promoção e prevenção na saúde dessa população (Brasil, 2009b).

A desinformação da população, crenças e valores arraigados sobre a patologia e seu prognóstico, bem como preconceito em relação ao toque retal, associados à falta de um exame específico e sensível que detecte na fase microscópica e a ausência de rotinas estratégicas na atenção primária pública e privada voltada para esses pacientes dificultam a detecção precoce da doença. $O$ homem, apesar do maior acesso à informação, enxerga o exame de forma constrangedora, mesmo entre grupos mais esclarecidos (Silva et al., 2015).

Como consequência, observa-se um grande número de diagnósticos tardios, com pior prognóstico e possibilidades reduzidas de intervenção terapêutica curativa. Sendo necessário assim, lançar mão de medidas paliativas que nem sempre atendem às expectativas do doente e de sua família. 


\section{METODOLOGIA}

O estudo foi realizado na Unidade de Oncologia do Hospital Márcio Cunha, situado no bairro Ferroviário, em Ipatinga, Minas Gerais e foi iniciado após aprovação do Comitê de Ética em Pesquisa do Centro Universitário do Leste de Minas Gerais (Unileste-MG), sob o protocolo 1058420. Este centro integra a estrutura da Fundação São Francisco Xavier (FSFX), braço social da Usinas Siderúrgicas de Minas Gerais (Usiminas). A unidade atende, mensalmente, aproximadamente 1600 pacientes do Vale do Aço e de outros 50 municípios da região.

Foram analisados prontuários de 767 pacientes atendidos nos anos de 2012, 2013 e 2014, conforme lista fornecida pela instituição, com diagnóstico de câncer da próstata cadastrados com CID-10 - C 61 (Neoplasia maligna da próstata). Deste total foram excluídos 99 prontuários de pacientes pois estes não tinham diagnóstico anatomopatológico realizado nos anos de 2012, 2013 e 2014 e aqueles prontuários que não tinham registro do diagnóstico anatomopatológico, totalizando 668 prontuários. Nos casos de ausência de mais alguma informação os dados serão trabalhados de acordo com o número de casos para cada variável avaliada.

Os prontuários foram analisados em horários pré-estabelecidos pela gerência da instituição para que não houvesse interferência e/ou prejuízos aos atendimentos dos pacientes ou na atividade administrativa da instituição. Os dados foram transcritos para o formulário (APÊNDICE A), para preenchimento das informações extraídas dos prontuários garantindo todo sigilo necessário ao estudo.

Para cada paciente foi preenchido um formulário contendo as seguintes variáveis: procedência, ano do diagnóstico, faixa etária, raça auto declarada, situação conjugal, fatores de risco como tabagismo, etilismo, história familiar de câncer da próstata (pai, irmão ou filho), PSA total ao diagnóstico, tipo histológico da biópsia prostática, padrão de Gleason da biópsia, Score de Gleason da biópsia distribuído em categoria de risco , tipo histológico da peça cirúrgica, padrão de 
Gleason da peça cirúrgica, Score de Gleason por categoria de risco da peça cirúrgica, tratamento realizado (prostatectomia radical, radioterapia, hormonioterapia, quimioterapia). A variável faixa etária foi estratificada em 5 grupos 41 a 50 anos; 51 a 60 anos; 61 a 70 anos; 71 a 80 anos e > 80 anos; estratificação semelhante à realizada por Al-Abdin et al. (2013) no seu estudo exceto pela presença da faixa $>80$ anos. A variável raça declarada foi dividida nas opções preta, parda, branca, amarela e indígena conforme censo 2010, do Instituto Brasileiro de Geografia e Estatística (IBGE, 2010a), vale ressaltar a dificuldade na coleta desta informação, no Brasil, devido à grande diversidade cultural e racial existente. O PSA total no diagnóstico foi estratificado em faixas sendo $<2,5 \mathrm{ng} / \mathrm{ml} ; 2,5 \mathrm{ng} / \mathrm{ml}$ a $4 \mathrm{ng} / \mathrm{ml} ; 4,1 \mathrm{ng} / \mathrm{ml}$ a $10 \mathrm{ng} / \mathrm{ml} ; 10,1 \mathrm{ng} / \mathrm{ml}$ a 20 $\mathrm{ng} / \mathrm{ml}$ e $>20 \mathrm{ng} / \mathrm{ml}$. O Score de Gleason do material obtido pela biópsia e análise da peça cirúrgica foi distribuído também por categoria de risco sendo estratificada em Score de Gleason 2 a 4; 5 a 6; 7 e 8 a10 (McAninch; Lue, 2014; Ribeiro et al., 2013).

Os dados foram analisados empregando-se estatística descritiva e inferencial. Para análise estatística, foi utilizado o software SPSS, versão 19.0. As variáveis quantitativas foram descritas através de média, desvio padrão e quartil. Já as variáveis qualitativas foram descritas através de frequência absoluta e relativa. A normalidade das amostras foi verificada através do teste de Kolmogorov Smirnov. Foi aplicado o Teste $t$ independente e teste de Mann Whitney para comparação dos grupos. Para associação entre as variáveis utilizou-se o teste qualitativo do Qui quadrado. O nível de significância adotado foi de $5 \%$, sendo considerado significativo valor de $p \leq 0,05$.

Os dados foram apresentados de forma descritiva e ilustrados por meio de TABELAS e FIGURAS. 


\section{RESULTADOS E DISCUSSÃO}

Neste estudo foi realizado a caracterização sócio demográfica dos pacientes e as comparações, correlações e associações entre aspectos relacionados aos fatores risco, níveis de PSA e anatomia patológica.

Na TAB. 1 destacou-se as cidades de origem dos pacientes atendidos na Unidade de Oncologia do Hospital Márcio Cunha, nos períodos de 2012 a 2014, contemplando ao todo 38 municípios. Pode-se observar que a maioria deles encontram-se distribuídos entre as micro regiões de Saúde composta pelas cidades de Ipatinga (39,7\%), Coronel Fabriciano (8,3\%) e Timóteo $(9,2 \%)$, munícipios estes considerados mais populosos desta micro região.

TABELA 1 - Distribuição dos pacientes segundo a procedência geográfica

\begin{tabular}{lcc}
\hline Variáveis & $\mathrm{N}$ & $\%$ \\
\hline Ipatinga & 281 & 39,7 \\
Timóteo & 65 & 9,2 \\
Coronel Fabriciano & 59 & 8,3 \\
Periquito & 44 & 6,2 \\
Caratinga & $\mathbf{2 6}$ & $\mathbf{3 , 7}$ \\
Belo Oriente & 24 & 3,4 \\
Inhapim & $\mathbf{2 4}$ & $\mathbf{3 , 4}$ \\
Santana do Paraíso & 19 & 2,7 \\
Sem informação & 16 & 2,3 \\
Mesquita & 13 & 1,9 \\
Açucena & 11 & 1,6 \\
lapu & 10 & 1,4 \\
Braúnas & 9 & 1,3 \\
Ubaporanga & $\mathbf{9}$ & $\mathbf{1 , 3}$ \\
Dionísio & 8 & 1,1 \\
Ipaba & 7 & 1,0 \\
São Domingos das Dores & $\mathbf{6}$ & $\mathbf{0 , 9}$ \\
Dom Cavati & 6 & 0,9
\end{tabular}




\begin{tabular}{|c|c|c|}
\hline Variáveis & $\mathrm{N}$ & $\%$ \\
\hline Piedade de Caratinga & 6 & 0,8 \\
\hline Entre Folhas & 5 & 0,7 \\
\hline Naque & 5 & 0,7 \\
\hline São Sebastião do Anta & 5 & 0,7 \\
\hline Antônio Dias & 5 & 0,7 \\
\hline Pingo D’Água & 4 & 0,6 \\
\hline Bom Jesus Do Galho & 4 & 0,6 \\
\hline Vargem Alegre & 4 & 0,6 \\
\hline Joanésia & 3 & 0,4 \\
\hline Imbé de Minas & 3 & 0,4 \\
\hline Marliéria & 3 & 0,4 \\
\hline São João Do Oriente & 3 & 0,4 \\
\hline Abadia dos Dourados & 3 & 0,4 \\
\hline Governador Valadares & 2 & 0,3 \\
\hline Manhuaçu & 2 & 0,3 \\
\hline Bugre & 2 & 0,3 \\
\hline Vermelho Novo & 2 & 0,3 \\
\hline Tarumirim & 2 & 0,3 \\
\hline Guanhães & 1 & 0,1 \\
\hline Jequitinhonha & 1 & 0,1 \\
\hline São Domingos Do Prata & 1 & 0,1 \\
\hline Córrego Novo & 1 & 0,1 \\
\hline Belo Horizonte & 1 & 0,1 \\
\hline Raul Soares & 1 & 0,1 \\
\hline Santa Bárbara do Leste & 1 & 0,1 \\
\hline Nova Era & 1 & 0,1 \\
\hline Total & 708 & 100 \\
\hline
\end{tabular}

Os pacientes provenientes das cidades em negrito, na TAB. 1 não pertencem às microrregiões de saúde referenciadas neste estudo, porém foram atendidas na Unidade de Oncologia do Hospital Marcio Cunha, pois esta presta atendimento aos usuários do SUS.

A FIG. 1 representa o mapa do Estado de Minas Gerais dividido em regiões, de acordo com o Censo 2010 (IBGE, 2010). A região que compreende a maioria dos municípios de origem dos pacientes analisados neste estudo é 
chamada de Vale do Rio Doce, com população estimada de 1.534 .268 mil habitantes e está localizada no leste do estado. As microrregiões de saúde estão localizadas na região do Vale do Rio Doce (FIG. 2 e 3).

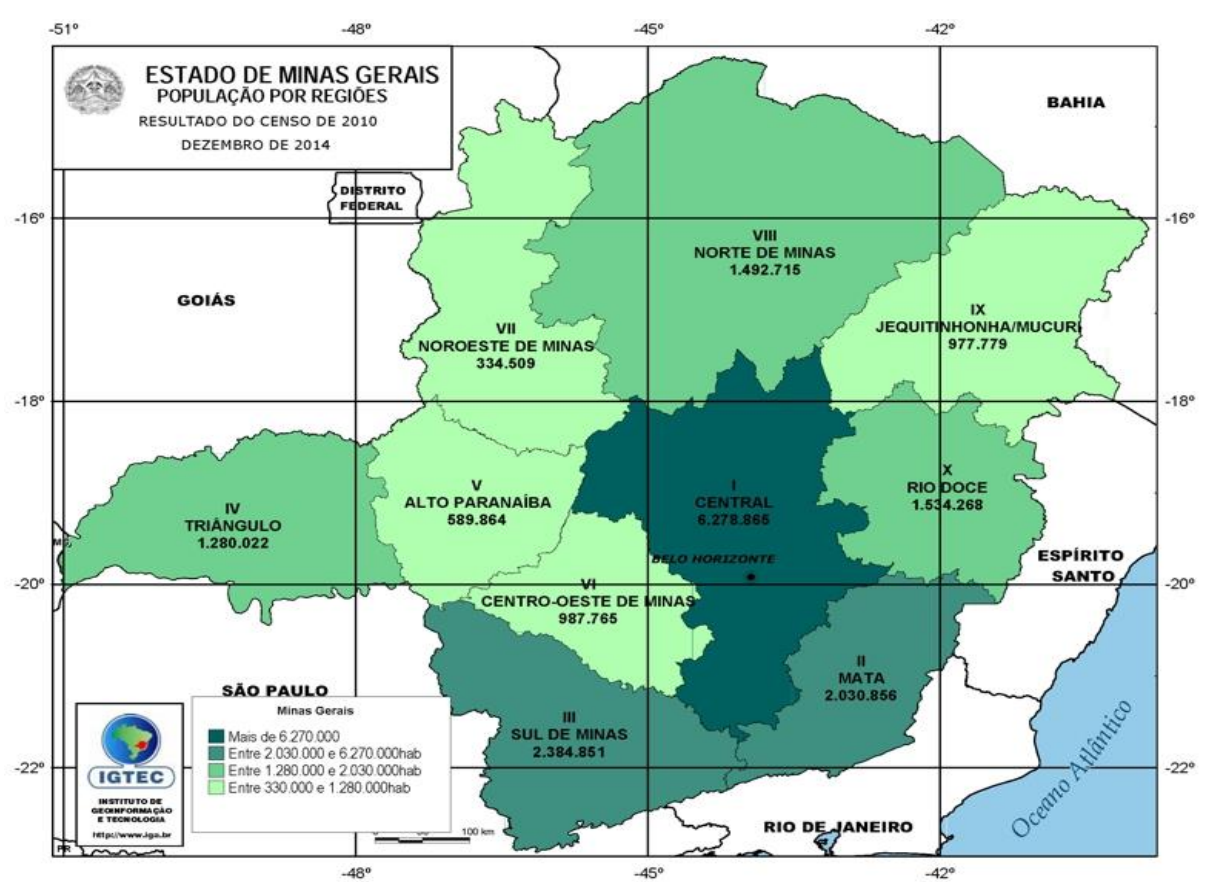

FIGURA 1 - Mapa do Estado de Minas Gerais ${ }^{1}$

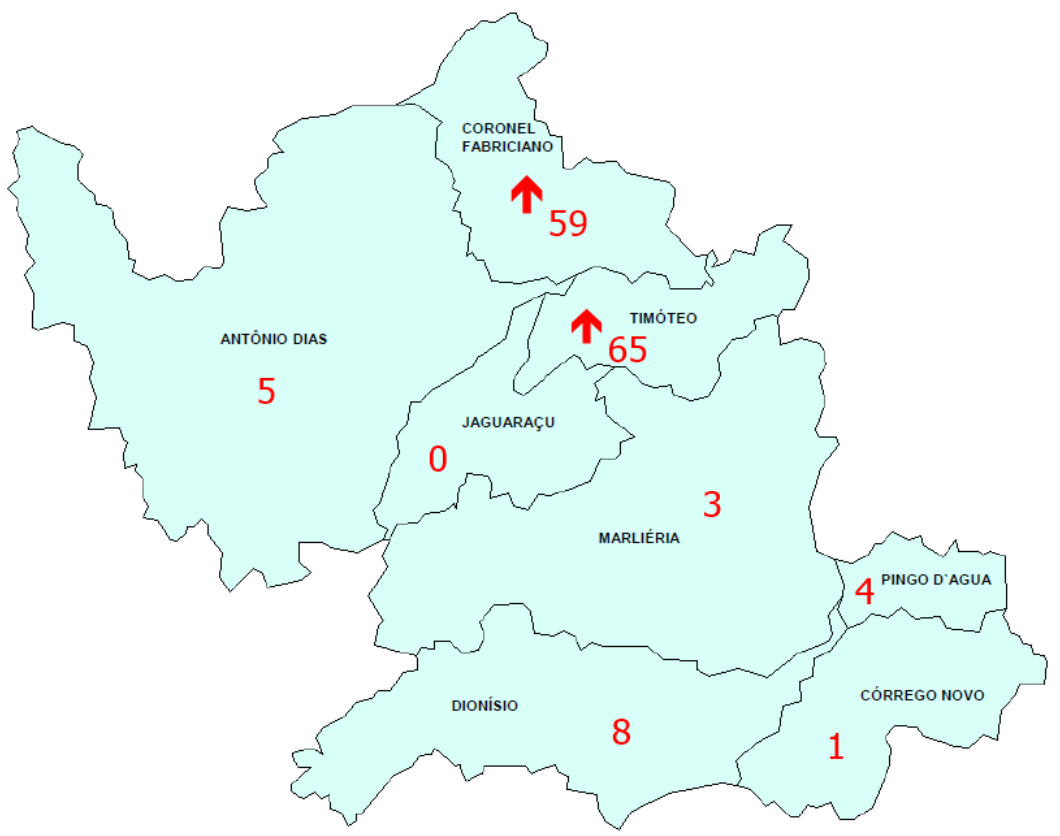

Fonte: SES/SMACSS/DEAA

Conforme Ajuste 2014

FIGURA 2 - Mapa da Microrregião de Coronel Fabriciano e Timóteo

\footnotetext{
${ }^{1}$ http://www.mg.gov.br/conheca-minas/geografiaAceaaa
} 


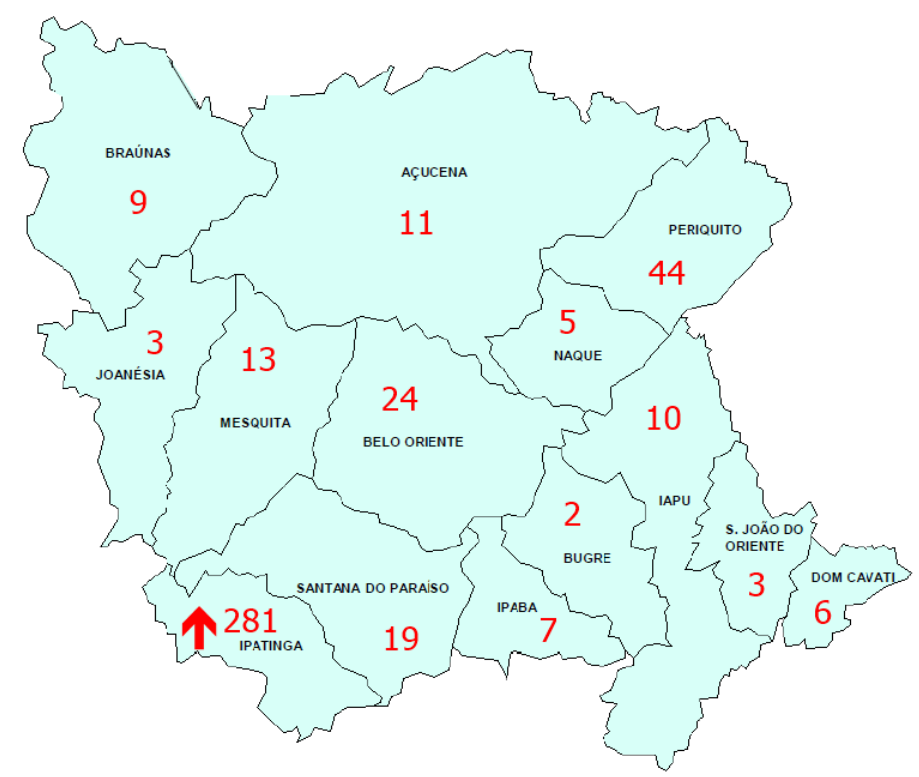

Fonte: SES/SMACSSIDEAA

Conforme Ajuste 2014

FIGURA 3 - Mapa da Microrregião de Ipatinga

A maior incidência de casos, foram provenientes das cidades mais populosas como Ipatinga com $39,7 \%$ dos casos.

Em um estudo epidemiológico de Câncer de Próstata na Índia também encontrou-se uma distribuição grande dos casos de câncer, e também com uma taxa maior nas cidades mais populosas (Jain; Saxena; Kumar, 2014).

De acordo Ribeiro et al. (2013), em um estudo epidemiológico no estado do Maranhão, também está registrado uma maior distribuição nas cidades mais populosas, e atribuiu essa incidência ao fato de ser mais fácil o acesso ao centro de Oncologia, pois a maioria morava na cidade sede do centro.

De um total de 708 pacientes, 99 foram excluídos; pois os prontuários não continham diagnóstico anatomopatológico realizado nos anos de interesse do estudo.

Foram então selecionados 668 prontuários de pacientes com câncer de próstata, atendidos nos anos de 2012 (39,4\%), 2013 (32,5\%) e 2014 (28,1\%), conforme está ilustrado na FIG. 4. 


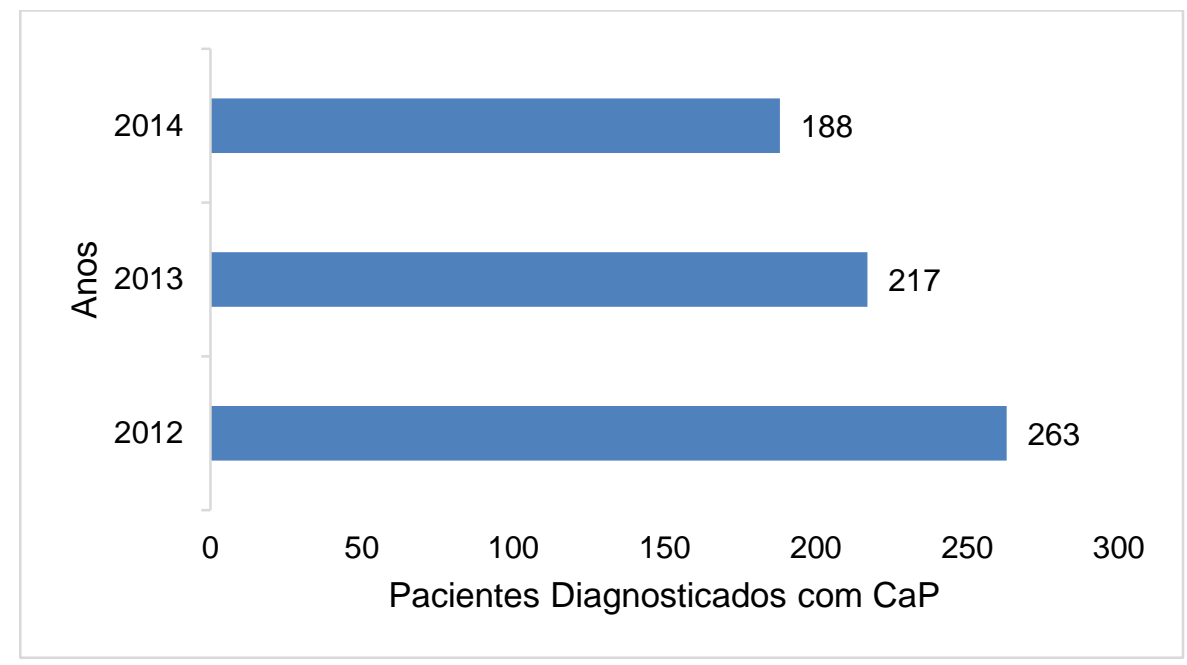

FIGURA 4 - Distribuição anual dos pacientes com Câncer de Próstata

Observa-se uma redução no número de casos de CaP nos anos estudados, fato que contradiz a literatura que relata o aumento dos casos nos últimos anos (INCA, 2016a; Ribeiro et al., 2013), fato, talvez explicado por deficiência no registro dos pacientes atendidos.

Em algumas correlações a seguir, ocorreu variações, no número total de pacientes, devido à falta de informações contidas nos prontuários dos pacientes.

Avaliando algumas características sócio demográficos do grupo selecionado para este estudo, pode-se observar (TAB. 2) que a maioria dos pacientes com CaP foram distribuídos nas faixas de 61 a 70 anos (34,8\%) e 71 a 80 anos $(33,8 \%)$.

TABELA 2 - Distribuição dos pacientes por faixa etária

\begin{tabular}{lcc}
\hline Faixa Etária (Anos) & $\mathrm{N}$ & $\%$ \\
\hline Entre 41 e 50 & 15 & 2,3 \\
Entre 51 e 60 & 127 & 19,1 \\
Entre 61 e 70 & 232 & 34,8 \\
Entre 71 e 80 & 225 & 33,8 \\
$>80$ & 67 & 10,0 \\
\hline Total & 666 & 100 \\
\hline
\end{tabular}

Considerando a caracterização sócio demográfica dos pacientes, foi analisada a faixa etária dos mesmos e encontrou-se uma prevalência maior entre 61 e 80 anos (TAB. 2). A literatura mostra que o envelhecimento é o fator de risco 
mais importante para CaP. Em homens com idade superior a 50 anos a incidência deste tipo de câncer é de $30 \%$ tendo um aumento significativo de $80 \%$ até aos 80 anos (Foster et al., 1997).

Os dados da pesquisa corroboraram com os dados apresentados por Cambruzzi et al. (2010) e Migowski e Silva (2010), nos Estados do Rio Grande do Sul e Rio de Janeiro, que encontraram na faixa etária de 60-69 anos, maiores percentuais de diagnósticos, correspondendo a 44,9\% e 48,4\% de suas amostras, respectivamente. Penaforte et al. (2010) nos estados de Pernambuco e Bahia (região do submédio São Francisco), revelaram uma maior concentração de pacientes com CaP na faixa de 70 a 79 anos (36,3\% da amostra analisada).

Gonçalves, Padovani e Pompin (2008); Ribeiro et al. (2013) e Fernandes et al. (2014) em seus trabalhos, observaram uma maior incidência de $\mathrm{CaP}$ na faixa etária entre 72 a 79 anos que entra em conformidade com a do presente estudo, onde a idade média variou entre 61 a 80 anos.

Dini e Koff (2006) em um estudo do perfil de CaP de próstata no Hospital das Clínicas $(\mathrm{HC})$ de Porto Alegre, também encontrou um aumento na incidência de $\mathrm{CaP}$ em indivíduos acima de 70 anos, com idade média de 65,8 anos variando de 48 a 86 anos de idade. Neste estudo a chance de se detectar o $\mathrm{CaP}$ em indivíduos com mais de 70 anos foi de cinco vezes maior do que nos indivíduos com idade inferior a 60 anos.

Segundo o INCA (2016b) mais do que qualquer outro tipo, o câncer da próstata é considerado um câncer da terceira idade, já que cerca de três quartos dos casos no mundo ocorrem a partir dos 65 anos.

Wu et al. (2017) avaliando 1788 paciente com CaP que foram submetidos a prostatectomia radical encontrou uma frequência de $46,9 \%$ de pacientes na faixa etária entre 55 e 65 anos e 33,4\% com mais de 65 anos.

Em relação a raça (TAB. 3), 2,4\% eram autodeterminados como negros, $93,2 \%$ pardos, $4,4 \%$ brancos.

TABELA 3 - Distribuição do grupo por raças.

\begin{tabular}{lcc}
\hline Raça & $\mathrm{N}$ & $\%$ \\
\hline Negra & 11 & 2,4 \\
Parda & 425 & 93,2 \\
Branca & 20 & 4,4 \\
\hline Total & 456 & 100 \\
\hline
\end{tabular}


Em relação à raça, são apresentados faixas de risco classificados em alto, intermediário e baixo, situando-se os negros norte-americanos na primeira, os brancos na segunda e os japoneses que vivem no Japão na terceira. Há um aumento na incidência entre os Japoneses que migraram para os Estados Unidos, esse aumento poderia estar relacionado com fatores ambientais e alimentares desse grupo (Barrios, 1996; Dini; Koff, 2006).

Antonopoulos et al. (2002) em um estudo que avaliou a diferença racial na prevalência do $\mathrm{CaP}$, demostrando que a prevalência em negros foi maior que em brancos.

Outros estudos relacionados à questão da etnia, mostraram que a incidência de $\mathrm{CaP}$ entre os negros é maior que entre os brancos; sendo a raça, o segundo fator de risco mais importante na gênese da doença (Siddiqui et al., 2006), estes autores relataram também uma mortalidade relacionada ao câncer 2,4 vezes maior na população afro-americana se comparado à raça branca (Siddiqui et al., 2006).

No presente estudo, encontra-se uma frequência alta de $\mathrm{CaP}$ entre a raça parda (TAB. 3), podendo ser justificado por um erro no momento de auto declarar a raça, confundindo negro com pardo e a incidência no negro foi bem menor quando comparada com o pardo e branco. Estes achados não vão de encontro com a maioria dos trabalhos da literatura que abordam este tema.

Neste mesmo contexto, Martins et al. (2000) e Romero (2012) avaliando essa relação, encontraram resultados semelhantes ao do presente estudo, não encontrando diferenças na prevalência de câncer de próstata entre negros e brancos no Brasil, estes dados corroboram, porém também não foram justificados.

Jemal et al. (2010) afirmam que as taxas de incidência e de mortalidade por câncer de próstata são maiores em negros e afro-americanos do que em outros grupos étnicos. Contrariando os dados observados nesse estudo, em que o grupo mais acometido foi dos que se autodeclararam pardos.

Piantino et al. (2014), num levantamento clínico-epidemiológico em um hospital de referência na cidade de Passos, MG, encontrou os seguintes resultados: $77,7 \%$ da amostra eram brancos, $19,6 \%$ negros, $4,3 \%$ pardos e $2,1 \%$ não possuíam informações quanto à cor. 
Outra mostra da dificuldade de caracterização da população brasileira devido às características de cada região do país foi o estudo de Souza, Almeida e Oliveira (2013) realizado no Estado do Pará, com $82 \%$ da cor parda, 10\% negra e $8 \%$ branca. Diferentemente desses dados, Migowski e Silva (2010) num estudo do tipo coorte, composto por 258 pacientes do Instituto Nacional do Câncer na cidade do Rio de Janeiro entre os anos de 1990 a 1999, na variável cor da pele tiveram uma amostra que se declarou branca em $75,2 \%$, parda em $18,6 \%$ e negra em $6,2 \%$.

Segundo dados do censo (IBGE, 2010b), no Brasil, a raça negra quando comparada às demais raças possui renda familiar inferior, menor escolaridade e menos acesso aos serviços de saúde. Conforme Nardi et al. (2012) esses fatores provavelmente contribuem com uma apresentação mais desfavorável da doença nesta população.

Na TAB. 4 foi analisado a relação da história familiar com o câncer de próstata e foi encontrado $17,2 \%$ de parentes de primeiro grau com câncer da próstata; sendo o pai em $37,3 \%$, o irmão em $60,8 \%$ e filho em $1,9 \%$.

TABELA 4 - Histórico familiar relacionado ao diagnóstico de câncer de próstata

\begin{tabular}{lcc}
\hline História Familiar & $\mathrm{N}$ & $\%$ \\
\hline Sim & 108 & 17,2 \\
Não & 520 & 82,8 \\
\hline Total & 628 & 100 \\
\hline Parentesco & $\mathrm{N}$ & $\%$ \\
\hline Pai & 38 & 37,3 \\
Irmão & 62 & 60,8 \\
Filho & 2 & 1,9 \\
\hline Total & 102 & 100 \\
\hline
\end{tabular}

No que diz respeito ao histórico familiar e a incidência de $\mathrm{CaP}$, Madersbacher et al. (2010), em seus estudos, mostrou uma correlação importante entre a ocorrência do câncer de próstata ao histórico familiar. Abouassaly et al. (2007) demonstraram que de $30 \%$ a $40 \%$ dos casos, de CaP diagnosticados em pacientes com menos de 55 anos foram de origem hereditária e que 5\% a 10\% apresentaram suscetibilidade genética. Gomes et al. (2008) em seus estudos 
postulou que a maioria dos casos de CaP ocorre em pacientes acima de 50 anos e com histórico familiar de pai ou irmão com $\mathrm{CaP}$.

Neste estudo, somente 108 dos 628 pacientes estudados apresentaram histórico familiar da doença, sendo 17,2\% de parentes de primeiro grau; deste total identificou-se o grau de parentesco em 102 pacientes; sendo o pai em $37,3 \%$, o irmão em $60,8 \%$ e filho em $1,9 \%$.

Saarimäki et al. (2015) encontraram uma frequência de 13,6\% de histórico familiar positivo de um total de 235 pacientes com CaP Este mesmo estudo mostrou que pacientes com histórico familiar tinham um risco um pouco maior de desenvolver CaP após um seguimento de 12 anos.

$\mathrm{Na}$ TAB. 5 estão apresentadas as frequências de pacientes com história de etilismo e tabagismo: $74,1 \%$ dos pacientes não tinham história de tabagismo e 79,2\% dos pacientes não apresentavam história de etilismo.

TABELA 5 - Frequências do etilismo e do tabagismo nos pacientes com CaP.

\begin{tabular}{lcccc}
\hline & \multicolumn{2}{c}{ Tabagismo } & \multicolumn{3}{c}{ Etilismo } \\
\hline Sim & $\mathrm{N}$ & $\%$ & 132 & $\%$ \\
Não & 165 & 25,9 & 503 & 20,8 \\
\hline Total & 473 & 74,1 & 635 & 79,2 \\
\hline
\end{tabular}

O tabagismo pode estar ligado ao início de vários tipos de cânceres e é considerado um importante fator de risco para câncer de próstata. Existem poucos dados sobre o hábito de fumar e seus efeitos no desenvolvimento do tumor. Alguns estudos recentes têm ligado o tabagismo a um possível pequeno aumento no risco de morte por câncer de próstata, mas esta é uma nova descoberta que terá de ser confirmada por mais estudos (INCA, 2016b).

No presente estudo, dos 638 pacientes avaliados, apenas 165 (25,9\%) eram fumantes (TAB. 5). Fernández et al. (2005) em seus estudos não observou relação estatística significativa de risco de câncer de próstata com o hábito de fumar.

Farmer (2008) em um estudo epidemiológico e fatores de risco sobre $\mathrm{CaP}$, encontraram dados inconsistentes sugerindo que o tabagismo poderia não ser um fator de risco para este tipo de câncer, apesar de ser considerado um dos mais importantes fatores de risco para a grande maioria dos canceres existentes. 
O US Department of Health and Human Services (2004), em alguns estudos encontraram uma associação entre o hábito de fumar e a mortalidade relacionada ao câncer de próstata, porém não foi encontrada nenhuma relação com o aumento da incidência de CaP.

Zu e Giovannucci (2009) acordam que em fumantes são encontrados tumores em estágios mais avançados com maior risco de doença severa e que o uso do tabaco poderia ser um indicador de um mal prognóstico, mas também não relacionam o cigarro com o aumento da incidência de CaP.

Segundo Fernandes et al. (2014), em um total de 54 pacientes com câncer de próstata analisados $28 \%$ relataram histórico de tabagismo.

Ho et al. (2014) pesquisaram se o hábito de fumar tinha relação com o $\mathrm{CaP}$, sugeriram que o mesmo não estava relacionado com diagnóstico global do câncer de próstata, mas foi associado com um risco aumentado de $\mathrm{CaP}$ mais agressivos.

Islami et al. (2014) em uma meta-análise, avaliaram 50.349 pacientes com CaP e observaram uma modesta relação do tabagismo com a incidência do $\mathrm{CaP}$, e foi identificada uma forte associação com a presença de tumores mais agressivos. Huncharek et al. (2010) em outra meta-análise, encontraram um risco de morte entre 24 a $30 \%$ maior entre fumantes com $\mathrm{CaP}$, mas não encontraram aumento na incidência.

Ainda, na TAB. 5, pode-se observar que a maioria dos pacientes com câncer de próstata não eram etilista (503) de um total de 635 que corresponde a $79,2 \%$ dos pacientes.

Esses dados corroboram com a literatura que sugere, na maioria dos trabalhos, não existir relação entre o aumento da incidência de câncer de próstata e o consumo de álcool (Breslow; Weed, 1998). Barba et al. (2004) em seus estudos não encontraram relação do consumo de álcool e o CaP. Gong et al. (2009) sugeriram que o consumo elevado de álcool diariamente aumenta o risco de câncer de próstata em grau mais avançado, no entanto não relaciona com o aumento da incidência.

Sesso et al. (2001) acompanharam prospectivamente 7.612 ex-alunos da escola de Havard entre 1988 e 1993, e contrariando a maioria dos estudos, encontrou uma associação positiva entre o consumo moderado de álcool e o CaP. 
Putnam et al. (2000) também encontraram uma associação entre o etilismo e a incidência do CaP, independente do tipo de bebida alcoólica.

Outro parâmetro avaliado foi o PSA total ao diagnóstico (TAB. 6). Observou-se que em $65,6 \%$ dos pacientes, o valor estava entre $4,1 \mathrm{ng} / \mathrm{ml}$ e $20 \mathrm{ng} / \mathrm{ml}$, sendo a maior frequência entre $4,1 \mathrm{ng} /$ e $10 \mathrm{ng} / \mathrm{ml}$ correspondendo a $49,5 \%$, ou seja, quase a metade da amostra.

TABELA 6 - Distribuição dos pacientes de acordo com os níveis de PSA sérico total ao diagnóstico por faixas $(\mathrm{ng} / \mathrm{ml})$

\begin{tabular}{lcc}
\hline PSA Total ao Diagnóstico $(\mathrm{ng} / \mathrm{ml})$ & $\mathrm{N}$ & $\%$ \\
\hline$<2,5$ & 9 & 1,4 \\
Entre 2,5 e 4 & 79 & 12,0 \\
Entre 4,1 e 10 & 325 & 49,5 \\
Entre 10,1 e 20 & 106 & 16,1 \\
$>20$ & 138 & 21 \\
\hline Total & 657 & 100
\end{tabular}

Segundo Catalona et al. (1997) existe tradicionalmente uma dosagem de PSA sérico que se localiza em uma zona de dúvida, PSA entre 4,1 e 10,0 $\mathrm{ng} / \mathrm{ml}$, nesta dosagem os pacientes são considerados suspeitos para câncer de próstata, mais recentemente esta dosagem tem sido definida entre 2,5 e 10,0 $\mathrm{ng} / \mathrm{ml}$.

Segundo Nassif et al. (2009) de 500 pacientes diagnosticados com CaP avaliados no período de 2000 - 2006, na Universidade Federal do Paraná, $11 \%$ apresentou PSA $<4 \mathrm{ng} / \mathrm{ml}, 70 \%$ PSA entre $4-10 \mathrm{ng} / \mathrm{ml}, 13 \% 10-20 \mathrm{ng} / \mathrm{ml}$ e $6 \%$ PSA > $20 \mathrm{ng} / \mathrm{ml}$. Migowskil e Silva (2010) encontraram as seguintes faixas de PSA ao diagnóstico: em um total de 246 pacientes avaliados 9,8\% apresentaram PSA < 4ng/ml, 32,5\% PSA entre 4,1-10ng/ml, 28\% PSA 10,1-20ng/ml, 16,3\% PSA entre $20,1-40 \mathrm{ng} / \mathrm{ml}$ e $13,4 \%$ PSA > 40ng $/ \mathrm{ml}$.

Corroborando com a presente pesquisa, Colberg et al. (1993), Krumholtz et al. (2002) e Ribeiro et al. (2013), observaram que a maioria da amostra estudada apresentava níveis de PSA entre 4,1 e $10 \mathrm{ng} / \mathrm{ml}$. Já Castro et al. (2011), em seus estudos encontraram níveis de PSA $8,9 \mathrm{ng} / \mathrm{ml}$ na maioria dos pacientes com positividade para CaP, ficando a grande maioria entre 4,1 e 10,0 $\mathrm{ng} / \mathrm{ml}$. 
O tipo histológico identificado em todos os 668 pacientes da presente amostra foi o adenocarcinoma acinar prostático.

Para a classificação histológica do câncer de próstata é utilizado o Score de Gleason que consiste em uma graduação crescente de diferenciação dos tumores variando entre 2-10. Sendo 2-6 tumores de baixo risco, 7 tumores de risco intermediário e 8-10 tumores de alto risco (Thompson et al., 2006; McAninch; Lue, 2014; Ribeiro et al., 2013).

Ao analisar-se a distribuição do estadiamento patológico (Score de Gleason) do material obtido por biópsia transretal da próstata (TAB. 7), observouse que o maior número de biópsias apresentava Gleason de 2 a $6(51,2 \%)$ e 7 $(32,1 \%)$.

O número de pacientes com Score de Gleason foi menor que o da amostra total, em cinco prontuários encontrou-se o diagnóstico do tipo histológico do tumor, e não foi encontrado o registro do Score de Gleason.

TABELA 7 - Distribuição do estadiamento patológico (Score de Gleason) do material obtido por biópsia transretal da próstata

\begin{tabular}{lcc}
\hline Estadiamento de Gleason da Biópsia & $\mathrm{n}$ & $\%$ \\
\hline 2 a 4 & 4 & 0,6 \\
5 a 6 & 335 & 50,6 \\
7 & 213 & 32,1 \\
8 a 10 & 111 & 16,7 \\
\hline Total & 663 & 100 \\
\hline
\end{tabular}

Tal achado foi corroborado por Ribeiro et al. (2013), que em seu estudo analisando as biópsias prostáticas, constatou-se que a maioria dos pacientes apresentou Score de Gleason igual a 6 e 7. O estudo de Martin et al. (2012) também corrobora com os achados da atual pesquisa, em que a maioria da amostra estudada apresentou Gleason 7, indicando um risco intermediário dos tumores. De acordo com Zacchi et al. (2014), em um total de 1.320 pacientes com CaP; 54\% apresentou Gleason $\leq 6,25 \%$ Gleason 7 e 21\% Gleason entre 8-10.

Do total de 220 pacientes que foram submetidos a prostatectomia radical no presente estudo, foi obtida informação referente ao tipo histológico de 207 pacientes sendo que destes 206 eram adenocarcinoma acinar prostático e em um paciente não foi identificado neoplasia. 
TABELA 8 - Tipo histológico da peça cirúrgica

\begin{tabular}{lcc}
\hline Tipo Tumoral Anatomopatológico & $\mathrm{N}$ & $\%$ \\
\hline Adenocarcinoma & 206 & 99,5 \\
Ausência de Neoplasia & 1 & 0,5 \\
\hline Total & 207 & 100 \\
\hline
\end{tabular}

Analisando o padrão do Score de Gleason da peça cirúrgica, observase uma distribuição parecida com a obtida no material de biópsia com a maioria dos pacientes apresentando Score de Gleason entre 2 e 6 (60,6\%) e 7 (36,5\%).

TABELA 9 - Distribuição do estadiamento patológico (Score de Gleason) da peça cirúrgica

\begin{tabular}{lcc}
\hline Estadiamento de Gleason da peça cirúrgica & $\mathrm{N}$ & $\%$ \\
\hline 2 a 4 & 0 & 0 \\
5 e 6 & 123 & 60,6 \\
7 & 74 & 36,5 \\
8 a 10 & 6 & 2,9 \\
\hline Total & 203 & 100 \\
\hline
\end{tabular}

Cambruzzi et al. (2010) analisando a histopatologia de 118 pacientes submetidos a prostatectomia radical observou um Score de Gleason com a seguinte distribuição: $54,24 \% \leq 6 ; 29,66 \%=7$ e 16,1\% entre 8-10.

Ao se comparar o Score de Gleason da biópsia com o Score de Gleason da peça cirúrgica (TAB. 10) foi observado o mesmo Score de Gleason em $70 \%$ dos pacientes, um aumento do Score de Gleason em 18,7\% e uma redução em $11,3 \%$ dos pacientes. Apesar de ter ocorrido esta diferença ela não foi estatisticamente significante, conforme observado na FIG. 5.

TABELA 10 - Nível de concordância do Score de Gleason entre material obtido na biópsia e peça cirúrgica 


\begin{tabular}{lcc}
\hline Nível de concordância do Score de Gleason entre & $\mathrm{N}$ & $\%$ \\
material obtido na Biópsia e peça cirúrgica & 142 & 70 \\
\hline Não houve & 38 & 18,7 \\
Aumento do Gleason & 23 & 11,3 \\
Redução do Gleason & 203 & 100 \\
\hline Total & & \\
\hline
\end{tabular}

Ribeiro et al. (2013) e Moreira et al. (2012), também encontraram o mesmo Score de Gleason para ambas, biópsia e peça cirúrgica, na maioria dos pacientes estudados. Ao comparar os resultados histológicos da biópsia prostática com os da peça cirúrgica, obteve-se concordância de 70,6\% e 72,86\% respectivamente.

Rapit et al. (2013) analisando 371 pacientes que foram submetidos a prostatectomia radical, observou concordância do Score de Gleason da biópsia e da peça cirúrgica em $67 \%$ dos pacientes, supergraduação em $7 \%$ e subgraduação em $26 \%$ dos pacientes.

San Francisco et al. (2003) também compararam o Score de Gleason de 311 pacientes submetidos à prostatectomia radical com a biópsia, encontrando concordância do Gleason em 67\%, supergraduação em 11\% e subgraduação em $22 \%$ dos pacientes.

Segundo Thickman et al. (1996) e Rajinikanth et al. (2008) existe diferença significativa entre os Score de Gleason, determinados pela biópsia da próstata e os Score de Gleason, com base no espécime anatomopatológico. Tem sido observado que o Score de Gleason de biópsias por agulha subestima o Score de Gleason do espécime de prostatectomia radical em 19 a $57 \%$ de todos os casos dependendo da série e os períodos examinados. Os autores encontraram vários fatores que poderiam estar influenciando nesta diferença, como por exemplo níveis de PSA, idade do paciente, resultado do toque retal, volume da próstata e a expertise do patologista.

Apesar de ter ocorrido certa discordância entre os Scores de Gleason da biópsia e da peça cirúrgica, quando realizou-se a comparação entre o Score de Gleason da biópsia com Score de Gleason da peça cirúrgica (próstata) enviada para exame anatomopatológico e aplicou-se o Teste " $f$ ' independente, não observou-se diferenças estatisticamente significantes entre os dois grupos (FIG. 5). 


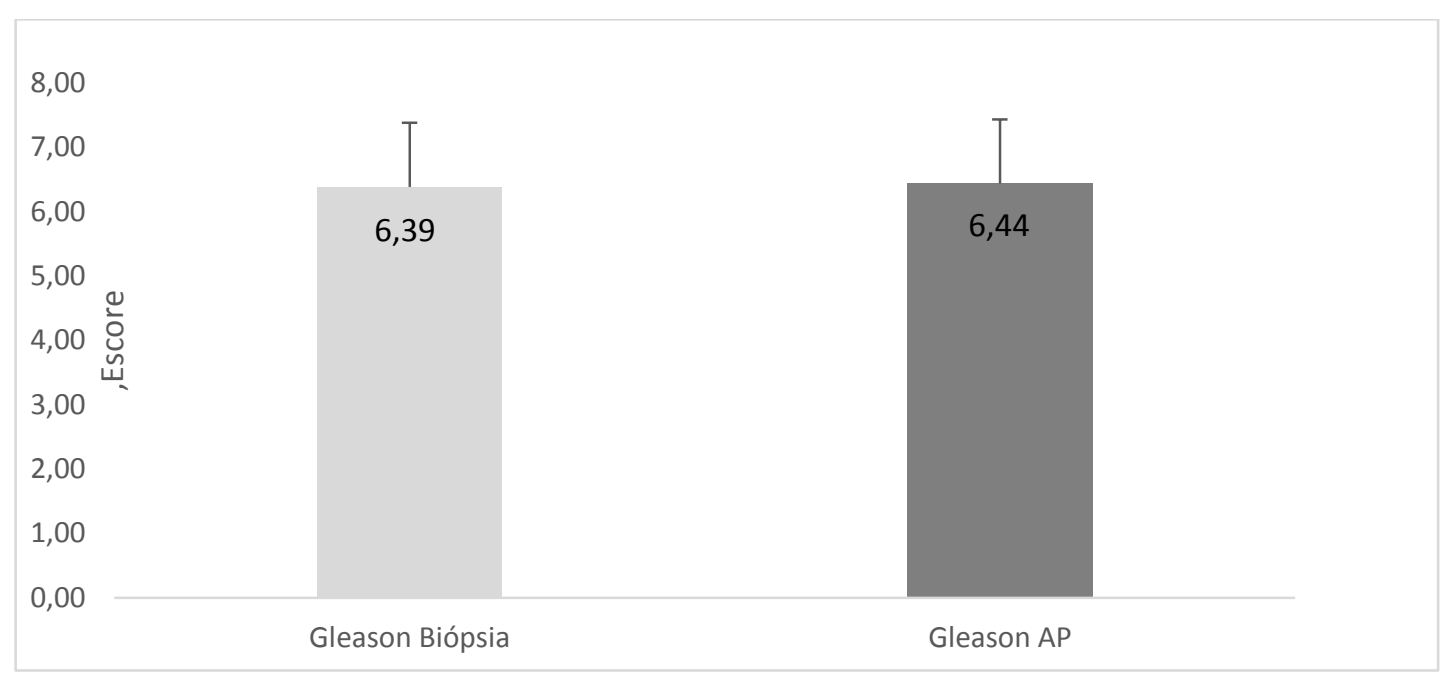

FIGURA 5 - Comparação entre valores do Score de Gleason da biópsia e da peça cirúrgica (AP). $P=0,249$. Teste $t$ independente ${ }^{*} p \leq 0,05$

Durante o momento da análise dos prontuários, 576 pacientes $(86,3 \%)$ estavam fazendo acompanhamento regular, $33(4,9 \%)$ tinham evoluído a óbito e $59(8,8 \%)$ não tinham registro no prontuário de regularidade do acompanhamento médico (TAB. 11).

TABELA 11 - Levantamento da situação do paciente.

\begin{tabular}{lcc}
\hline Situação do Paciente & $\mathrm{N}$ & $\%$ \\
\hline Tratamento & 576 & 86,3 \\
Foi a Óbito & 33 & 4,9 \\
Sem registro & 59 & 8,8 \\
Total & 668 & 100 \\
\hline
\end{tabular}

No Brasil, pacientes com doença localizada apresentam sobrevida média de cinco anos, em $88 \%$ dos casos e de 10 anos, em $71 \%$. Aqueles estratificados como de alto risco apresentam um pior prognóstico (Migowski; Silva, 2010). Zacchi et al. (2014) em estudo conduzido em um serviço de referência do Espírito Santo, de uma amostra de 1.290 homens, 308 (23,8\%) foram a óbito pela doença, $224(17,3 \%)$ faleceram de outras causas e 758 $(58,7 \%)$ encontravam-se vivos ao término do período de tratamento. Dentre os sobreviventes, $267(20,6 \%)$ não realizaram o seguimento mínimo de cinco anos.

$\mathrm{Na}$ presente pesquisa, foram obtidas informações sobre a situação clínica dos pacientes com CaP nos três anos pesquisados, não podendo, 
portanto, ter informações sobre sobrevida em cinco anos e nem sequer ter a certeza se os óbitos observados estavam relacionados diretamente ao câncer.

Em relação a fonte pagadora do tratamento (TAB. 12), $79,5 \%$ dos pacientes eram do SUS, 19\% eram de planos de saúde, 0,6\% eram particulares e 0,9\% não tinham a fonte pagadora informada no prontuário.

TABELA 12 - Fonte pagadora do tratamento

\begin{tabular}{lcc}
\hline Fonte Pagadora & $\mathrm{N}$ & $\%$ \\
\hline SUS & 531 & 79,5 \\
Plano de Saúde & 127 & 19,0 \\
Particular & 4 & 0,6 \\
Sem informação & 6 & 0,9 \\
\hline Total & 668 & 100 \\
\hline
\end{tabular}

Os dados da pesquisa foram superiores aos encontrados no estudo de Zacchi et al. (2014), no qual $61 \%$ dos pacientes vieram encaminhados pelo SUS e $39 \%$ eram de outros serviços. Os dados deste estudo confirmam a vocação da unidade de atendimento que recebe pacientes do SUS, proveniente de duas importantes microrregiões de saúde localizadas no leste de Minas Gerais e de municípios próximos.

Relacionando os níveis de PSA total ao diagnóstico com as faixas de idade pode-se observa na TAB. 13 que quanto maior a faixa etária, maior o valor do PSA total dos pacientes com câncer da próstata. Como exemplo, na faixa etária de entre 41 e $50,75 \%$ dos pacientes tinham PSA total menor que $9,2 \mathrm{ng} / \mathrm{ml}$ e na faixa entre 71 e 80 anos, $75 \%$ dos pacientes tinham PSA total menor que $24,2 \mathrm{ng} / \mathrm{ml}$.

TABELA 13 - Níveis de PSA sérico dos pacientes relacionados a faixa etária

\begin{tabular}{lccccc}
\hline $\begin{array}{l}\text { Distribuição PSA Total ao } \\
\text { Diagnóstico (ng/ml) }\end{array}$ & $\mathrm{n}$ & $\bar{x} \pm s$ & Quartil 1 & Quartil 2 & Quartil 3 \\
\hline Faixa Etária (anos) & 15 & $6,8 \pm 3,7$ & 4 & 5,5 & 9,2 \\
Entre 41 e 50 & 125 & $9,3 \pm 12,9$ & 4 & 5,4 & 8,3 \\
Entre 51 e 60 & 226 & $21,7 \pm 72,8$ & 5 & 7 & 13,1 \\
Entre 61 e 70 & 222 & $92,3 \pm 337,7$ & 5,8 & 9,2 & 24,2 \\
Entre 71 e 80 & 66 & $74,1 \pm 209,1$ & 9 & 17,3 & 41,1 \\
$>80$ & & & & & \\
\hline
\end{tabular}


Ribeiro et al. (2013) observaram em seu estudo que os níveis de PSA dependem da faixa etária dos pacientes e tendem a aumentar com a idade. Castro et al., (2011) em seus estudos, também encontraram esse aumento, onde $75 \%$ dos pacientes avaliados tinham 65 anos ou mais. Kristal et al. (2006) também corroboraram com esses resultados, em seus estudos observaram que houve um aumento linear dos níveis de PSA com o aumento da idade, homens de idade de 70 anos e mais velhos tinham valores de PSA que eram $22 \%$ mais elevados em comparação com os valores em homens com idades entre 55-59 anos.

Quando analisou-se a relação do PSA total com a raça autodeterminada (TAB. 14) identificou-se que a maioria dos pacientes $(75 \%)$ do total dos pacientes da raça negra apresentavam PSA total inferior a $8,7 \mathrm{ng} / \mathrm{ml}$, da raça branca inferior $15,5 \mathrm{ng} / \mathrm{ml}$, da raça parda inferior a $37,3 \mathrm{ng} / \mathrm{ml}$. Esses resultados podem, talvez, serem explicados pelo erro na auto declaração da raça feita pelos pacientes.

TABELA 14 - Níveis de PSA sérico dos pacientes relacionados à raça

\begin{tabular}{lccccc}
\hline $\begin{array}{l}\text { Distribuição PSA Total ao } \\
\text { Diagnóstico }(\mathrm{ng} / \mathrm{ml})\end{array}$ & $\mathrm{N}$ & $\bar{x} \pm \boldsymbol{s}$ & Quartil 1 & Quartil 2 & Quartil 3 \\
\hline Raça & 11 & $8,5 \pm 7,2$ & 3,9 & 7,8 & 8,7 \\
Negro & 425 & $48,7 \pm 180,1$ & 10,5 & 16,2 & 37,3 \\
Pardo & 20 & $28,8 \pm 74,6$ & 4,4 & 7,5 & 15,5 \\
Branco & 456 & & & & \\
\hline Total & & & & & \\
\hline
\end{tabular}

Antonopoulos et al. (2002) em um estudo sobre câncer de próstata e a raça, descreveram que os negros têm níveis de PSA maiores quando relacionados aos brancos, Moul et al. (1995) também encontraram valores de PSA maiores em negros do que em brancos. Esses autores encontraram resultados contrários aos do presente estudo. No entanto, Kristal et al. (2006) em seus estudos não encontraram diferenças significativas nos níveis de PSA entre os afro-americanos, brancos e outros. Essa heterogeneidade pode ser atribuída às diferenças existentes em cada população estudada. 
Wu et al. (2017), em um estudo retrospectivo, também encontraram níveis de PSA maior (> 20ng/ml) em pacientes negros quando comparado aos brancos.

Após caracterização da amostra tornou-se necessário avaliar algumas correlações, comparações e associações relevantes entre os aspectos relacionados aos fatores de risco, níveis de PSA e anatomia patológica para esclarecer o perfil epidemiológico do grupo estudado.

Quando compara-se o PSA total dos pacientes ao diagnóstico com fatores de risco como tabagismo, etilismo e histórico familiar observa-se que 0 PSA total dos pacientes com histórico de etilismo era maior (mediana de 9,4ng/ml) do que o PSA dos que não possuíam histórico de etilismo (mediana de $7,5 \mathrm{ng} / \mathrm{ml}$ ) com nível de significância $\mathrm{p} \leq 0,05$. Nos outros grupos não houve diferenças estatisticamente significante (TAB. 15).

TABELA 15 - Comparação entre PSA total ao diagnóstico e fatores de risco

\begin{tabular}{lccc}
\hline \multirow{2}{*}{ PSA Total ao Diagnóstico $(\mathrm{ng} / \mathrm{ml})$} & Sim & Não & \multirow{2}{*}{ Valor P } \\
\cline { 2 - 3 } & Mediana & Mediana & \\
\hline Tabagismo & 7,9 & 7,8 & 0,76 \\
Etilismo & 9,4 & 7,5 & $0,05^{\star}$ \\
Histórico Familiar & 7,4 & 7,9 & 0,27 \\
\hline
\end{tabular}

Teste Mann Whitney ${ }^{*} p \leq 0,05$

Kristal et al. (2006) em seu estudo encontrou uma relação baixa entre o habito de fumar e os níveis de PSA e não encontrou relação significativa entre os outros fatores analisados no presente estudo. Contrariando os achados de Saarimaäki et al. (2015), que encontraram níveis de PSA maiores em pacientes com histórico familiar positivo para CaP

Analisando a associação entre Score de Gleason e fatores demográficos como faixa etária, identificou-se que na faixa etária entre 41 e 70 anos, mais da metade dos pacientes apresentaram Score de Gleason entre 2 e 6 e na faixa etária entre 71 e 80 anos e > 80anos, observou-se uma frequência de tumores de alto risco maior (Gleason de 8 a 10) que foi de 20,5\% e 26,2\% respectivamente (TAB. 16).

Houve diferenças estatisticamente significantes entre o Score de Gleason da biópsia e as faixas etárias analisadas $(p=0,032)$, ou seja, em faixas 
etárias mais elevadas, o Score de Gleason foi maior; o mesmo não foi observado quando analisado o Score de Gleason da peça cirúrgica ( $p=0,433)$ (TAB. 16).

Russo et al. (2012) encontraram algo semelhante em seus estudos. Eles observaram que homens com idade > 70 anos têm mais Gleason entre 8-10 quando comparados a homens com idade < 70 anos. Estes autores também encontraram uma relação direta como um maior risco de recorrência, metástases, aumento nos níveis de PSA e aumento da mortalidade. Draisma et al. (2006) também encontraram em seus estudos um aumento do Score de Gleason com aumento da faixa etária.

Em um estudo retrospectivo, realizado por Shah et al. (2016), onde foram avaliados 5100 pacientes com CaP, com idade entre 70 e 80 anos, encontrou-se uma frequência de $61 \%$ de Score de Gleason entre 7 - 10, indicando tumores mais agressivos em pacientes mais idosos.

TABELA 16 - Associação entre faixa etária e estadiamento de Gleason da biópsia e da peça cirúrgica.

\begin{tabular}{|c|c|c|c|c|c|c|c|c|c|c|}
\hline \multirow{3}{*}{ Faixa Etária (Anos) } & \multicolumn{8}{|c|}{ Estadiamento de Gleason biópsia } & \multirow{3}{*}{ Total } & \multirow{3}{*}{$\begin{array}{c}\text { Valor } \\
\mathrm{P}\end{array}$} \\
\hline & \multicolumn{2}{|c|}{2 a 4} & \multicolumn{2}{|c|}{5 e 6} & \multicolumn{2}{|c|}{7} & \multicolumn{2}{|r|}{8 a 10} & & \\
\hline & $\mathrm{n}$ & $\%$ & $\mathrm{n}$ & $\%$ & $\mathrm{n}$ & $\%$ & $n$ & $\%$ & & \\
\hline Entre 41 e 50 & 0 & 0 & 11 & 73,3 & 4 & 26,7 & 0 & 0 & 15 & \\
\hline Entre 51 e 60 & 1 & 0,8 & 77 & 60,6 & 36 & 28,3 & 15 & 10,2 & 127 & \\
\hline Entre 61 e 70 & 0 & 0 & 119 & 51,7 & 76 & 33 & 3 & 15,2 & 230 & $0,032^{*}$ \\
\hline Entre 71 e 80 & 2 & 0,9 & 101 & 45,1 & 75 & 33,5 & 4 & 20,5 & 224 & \\
\hline$>80$ & 1 & 1,5 & 25 & 38,5 & 22 & 33,8 & 17 & 26,2 & 65 & \\
\hline \multicolumn{11}{|l|}{ Qui Quadrado * $\mathrm{p} \leq 0,05$} \\
\hline \multirow{3}{*}{ Faixa Etária (Anos) } & \multicolumn{8}{|c|}{ Estadiamento de Gleason peça cirúrgica } & \multirow{3}{*}{ Total } & \multirow{3}{*}{ Valor P } \\
\hline & \multicolumn{3}{|c|}{5 e 6} & \multicolumn{3}{|c|}{7} & \multicolumn{2}{|c|}{8 a 10} & & \\
\hline & $\mathrm{n}$ & \multicolumn{2}{|r|}{$\%$} & $\mathrm{n}$ & \multicolumn{2}{|l|}{$\%$} & $\mathrm{n}$ & $\%$ & & \\
\hline Entre 41 e 50 & 8 & \multicolumn{2}{|r|}{53,3} & 7 & \multicolumn{2}{|c|}{46,7} & 0 & 0 & 15 & \multirow{4}{*}{0,433} \\
\hline Entre 51 e 60 & 45 & \multirow{2}{*}{\multicolumn{2}{|c|}{$\begin{array}{l}68,2 \\
56,4\end{array}$}} & 20 & \multicolumn{2}{|c|}{30,3} & 1 & 1,5 & 66 & \\
\hline Entre 61 e 70 & 53 & & & 36 & \multicolumn{2}{|c|}{38,3} & 5 & 5,3 & 94 & \\
\hline Entre 71 e 80 & 15 & \multicolumn{2}{|r|}{57,7} & 11 & \multicolumn{2}{|c|}{42,3} & 0 & 0 & 26 & \\
\hline
\end{tabular}

Em relação a raça (TAB. 17 e 18), independente da mesma, a maioria dos pacientes apresentou Score de Gleason nas faixas de 2 a 6 e Gleason 7 ou seja tumores bem diferenciados e moderadamente diferenciados respectivamente, sem diferenças estatisticamente significantes $p>0,05$ entre as raças. 
TABELA 17 - Associação entre raça e estadiamento de Gleason da biópsia

\begin{tabular}{|c|c|c|c|c|c|c|c|c|c|c|}
\hline \multirow{3}{*}{ Raça } & \multicolumn{9}{|c|}{ Estadiamento de Gleason Biópsia } & \multirow{3}{*}{$\begin{array}{c}\text { Valor } \\
\text { P }\end{array}$} \\
\hline & \multicolumn{2}{|c|}{2 a 4} & \multicolumn{2}{|c|}{5 e 6} & \multicolumn{2}{|c|}{7} & \multicolumn{2}{|c|}{8 a 10} & \multirow[t]{2}{*}{ Total } & \\
\hline & $\mathrm{n}$ & $\%$ & $\mathrm{n}$ & $\%$ & $\mathrm{n}$ & $\%$ & $\mathrm{n}$ & $\%$ & & \\
\hline Preto & 0 & 0 & 7 & 63,6 & 4 & 36,4 & 0 & 0 & 11 & \\
\hline Pardo & 3 & 0,7 & 198 & 47 & 137 & 32,5 & 83 & 19,7 & 421 & 0,794 \\
\hline Branco & 0 & 0 & 9 & 45 & 7 & 35 & 4 & 20 & 20 & \\
\hline
\end{tabular}

TABELA 18 - Associação entre raça e estadiamento de Gleason da peça cirúrgica

\begin{tabular}{|c|c|c|c|c|c|c|c|c|}
\hline \multirow{3}{*}{ Raça } & \multicolumn{6}{|c|}{ Estadiamento de Gleason peça cirúrgica } & \multirow{3}{*}{ Total } & \multirow{3}{*}{ Valor $\mathrm{P}$} \\
\hline & \multicolumn{2}{|c|}{5 e 6} & \multicolumn{2}{|c|}{7} & \multicolumn{2}{|c|}{8 a 10} & & \\
\hline & $\mathrm{n}$ & $\%$ & $\mathrm{n}$ & $\%$ & $\mathrm{n}$ & $\%$ & & \\
\hline Preto & 1 & 50 & 1 & 50 & 0 & 0 & 2 & \\
\hline Pardo & 48 & 53,9 & 38 & 42,7 & 3 & 3,4 & 89 & 0,964 \\
\hline Banco & 4 & 66,7 & 2 & 33,3 & 0 & 0 & 6 & \\
\hline
\end{tabular}

Qui Quadrado * $p \leq 0,05$

No estudo de Wu et al. (2017), avaliaram 1788 pacientes com CaP e encontrou-se uma associação estatisticamente significante quando se comparou o Score de Gleason de afro-americanos com caucasianos, sendo que entre os afro americanos o Score de Gleason $(\geq 7)$ foi maior, indicando que em negros o tumor tende a ser mais agressivo.

Hoffman et al. (2001) avaliaram 3.173 pacientes com CaP diagnosticados entre outubro de 1994 e outubro de 1995 e encontraram 16,8\% dos pacientes afro americanos com tumores indiferenciados (Score de Gleason 28) comparados com pacientes brancos não hispânicos que apresentaram uma distribuição de 10,5\% sendo estatisticamente significante.

$\mathrm{Na}$ comparação entre os fatores de risco pesquisados e o Score de Gleason da biópsia e da análise anatomopatológica da peça cirúrgica foi constatada uma diferença estatisticamente significante entre indivíduos fumantes que apresentaram Score de Gleason maior que os não fumantes na análise anatomopatológica da peça cirúrgica $(p=0,008)$. 
Entre os pacientes etilistas e não etilista houve diferenças estatisticamente significantes em relação ao Gleason da peça cirúrgica sendo maior nos etilistas $(p=0,002)$. E em relação ao histórico familiar não houve diferenças estatisticamente significantes entre o Score de Gleason da biópsia e da peça cirúrgica entre os pacientes com e sem histórico familiar.

TABELA 19 - Comparação entre Fatores de Risco e Score de Gleason da biópsia e análise anatomopatológica da peça cirúrgica

\begin{tabular}{|c|c|c|c|c|}
\hline \multirow{2}{*}{ Fatores de Risco } & \multirow{2}{*}{ Gleason } & Sim & Não & \multirow{2}{*}{ Valor $p$} \\
\hline & & $\bar{x} \pm \mathrm{s}$ & $\bar{x} \pm \mathrm{s}$ & \\
\hline \multirow{2}{*}{ Tabagismo } & Biópsia & $6,8 \pm 1,0$ & $6,7 \pm 1,0$ & 0,271 \\
\hline & Peça cirúrgica & $6,6 \pm 0,7$ & $6,4 \pm 0,5$ & $0,008^{*}$ \\
\hline \multirow[t]{2}{*}{ Etilismo } & Biópsia & $6,8 \pm 1,0$ & $6,7 \pm 1,0$ & 0,47 \\
\hline & Peça cirúrgica & $6,7 \pm 0,8$ & $6,4 \pm 0,5$ & $0,002^{*}$ \\
\hline \multirow{2}{*}{ Histórico Familiar } & Biópsia & $6,7 \pm 1,0$ & $6,8 \pm 1,0$ & 0,429 \\
\hline & Peça cirúrgica & $6,5 \pm 0,8$ & $6,4 \pm 0,6$ & 0,503 \\
\hline
\end{tabular}

Na literatura não há muitos dados relacionando estes fatores de risco com aumento no Score de Gleason. Ho et al. (2014) encontraram uma associação entre tumores mais agressivos (Gleason $\geq 7$ ) em pacientes fumantes magros (IMC $\leq 25 \mathrm{Kg} / \mathrm{m}^{2}$ ) submetidos a biópsia. Zu e Giovannucci (2009) em um estudo de revisão de epidemiologia, mostram que a maioria dos trabalhos prospectivos relatam um risco $30 \%$ maior de morte em pacientes fumantes indicando tumores mais agressivos.

Telang et al. (2017) em um estudo de revisão da literatura que relacionava histórico familiar com progressão do tumor, não encontraram relação entre o histórico familiar e CaP mais agressivo.

No trabalho que avaliou o braço Suíço do estudo ERSPC (European Randomised Study of Screnning for Prostat Cancer) onde foram acompanhados 4932 casos, durante 11 anos em média, não houve diferença estatisticamente significante entre Score de Gleason da biópsia ou da peça cirúrgica dos pacientes com e sem histórico familiar de CaP (Randazzo et al., 2015).

Saarimäk et al. (2015) em um estudo prospectivo, encontrou valores de Score de Gleason menores, ou seja, tumores menos agressivos, entre os 
pacientes com histórico familiar de $\mathrm{CaP}$, mas sem diferenças estatisticamente significantes na mortalidade entre os dois grupos.

Em estudo prospectivo realizado por Sawada et al. (2014) no Japão, foram acompanhados 48218 homens, durante 16 anos, dos quais 913 desenvolveram $\mathrm{CaP}$, foi encontrada uma relação estatisticamente significante entre etilismo e presença de tumores de próstata mais agressivos (Score de Gleason $\geq 8$ ) e em relação ao tabagismo não foi encontrado relação estatisticamente significante neste estudo. 


\section{CONCLUSÃO}

- Houve concordância entre Score de Gleason da biópsia e da peça cirúrgica em $70 \%$ dos casos, uma subgraduação em $18,7 \%$ e uma supergraduação em $11,3 \%$;

- Quanto maior foi a faixa etária dos pacientes maiores foram os valores do PSA total ao diagnóstico;

- Pacientes autodeclarados pardos apresentaram níveis de PSA total ao diagnóstico mais elevados;

- Pacientes etilistas apresentaram níveis de PSA total ao diagnóstico mais elevados;

- Quanto maior foi a faixa etária dos pacientes, maior foi o Score de Gleason do material obtido pela biópsia, ou seja, mais indiferenciado foi o tumor;

- Pacientes etilistas e tabagistas apresentaram Score de Gleason da peça cirúrgica mais elevado, ou seja, tumores mais indiferenciados;

Pelas pesquisas realizadas, constatou-se que este foi o primeiro estudo epidemiológico de $\mathrm{CaP}$ desenvolvido na região do Vale do Aço. A caracterização sócio demográfica e as associações aqui encontradas poderão contribuir com programas para desenvolver ações de controle do CaP nesta região. 


\section{APÊNDICE A - Formulário de coleta de dados}

1. Número do prontuário:

2. Nome do paciente: (preencher com as iniciais)

3. Idade ao diagnóstico: (anos)

4. Profissão:

5. Raça/cor segundo os critérios de auto declaração:
( ) Preto
( ) Pardo
( ) Branco
( ) Amarelo
( ) Indígena

6. Procedência:

7. Situação conjugal:
( ) Solteiro(a)
( ) Casado(a) / Vive com companheiro(a)
( ) Separado(a)/Divorciado(a)
( ) Viúvo(a)

8. Grau de escolaridade:
( ) Ensino Fundamental
( ) Ensino Médio
( ) Ensino Profissionalizante
( ) Ensino Superior
( ) Especialização.
( ) Mestrado.
( ) Doutorado

9. Tabagista?
( ) $\operatorname{sim}$
( ) não

Em caso positivo anotar informações importantes que estejam relacionadas 
10. Uso de bebida alcoólica:
( ) sim
( ) não

Em caso positivo anotar informações importantes que estejam relacionadas

11. História familiar de parentes de $1^{\circ}$ grau (pai, irmão, filho) com câncer de próstata?

( ) $\operatorname{sim}$ ( ) não

Em caso positivo informar o parentesco:

12. Quando foi feito o diagnóstico de câncer de próstata?

1

13. PSA total e livre ao diagnóstico:

PSA livre e total mais recente:

14. Tipo tumoral e Estadiamento da doença/escore de Gleason no diagnóstico:

Tipo:

Estadiamento/ escore de Gleason:

15. Histórico de doença prostática nos últimos 12 meses:

( ) HPB

( ) prostatite

( ) outras

16. No momento da pesquisa o paciente encontrava-se:

( ) em tratamento

( ) foi a óbito. Relacionado à doença? ( ) sim ( ) não

17. O paciente foi tratado pelo:
( ) SUS
( ) Plano de Saúde
( ) Particular
( ) Sem informação 


\section{REFERÊNCIAS BIBLIOGRÁFICAS}

ABOUASSALY, R.; THOMPSON JÚNIOR; I.M.; PLATZ, E.A.; KLEIN, E.A. Epidemiology, etiology, and prevention of prostate cancer. In: WEIN, A.J.; KAVOUSSI, L.R.; NOVICK, A.C.; PARTIN, A.W.; PETERS, C. A. (eds.) CampbellWalsh urology. 9. ed. Philadelphia: Saunders Elsevier, 2007, p. 2854-2857.

AL-ABDIN, O.Z.; RABAH, D.M.; BADR, G.; KOTB, A.; APRIKIAN, A. Differences in prostate cancer detection between Canadian and Saudi populations. Braz $\boldsymbol{J}$ Med Biol Res, v. 46, n. 6, p. 539-545, jun. 2013. Disponivel em: $<$ https://www.ncbi.nlm.nih.gov/pmc/articles/PMC3854441/>. Acesso em: 13 jan. 2017.

ALBERTS, B.; JOHNSON, A.; LEWIS, J.; RAFF, M.; ROBERTS, K.; WALTER, P. Biologia molecular da célula. 5 ed. Porto Alegre: ArtMed, 2010. 1054p

AMERICAN JOINT COMMITTEE ON CANCER. Staging Manual and the Future of TNM, $7^{\text {th }}$. Annals of Surgical Oncology, v. 17, June 2010, Issue 6, p. 14711474. Disponível em: <http://paperity.org/p/5833932/the-american-jointcommittee-on-cancer-the-7th-edition-of-the-ajcc-cancer-staging-manual>. Acesso em: 11 jul. 2016.

ANTONOPOULOS, J.M.; POMPEO, A.C.L.; GÓES P.M.; CHADE, J.; SARKIS A. S.; ARAP, S. Racial Differences in Prostatic Cancer Prevalence. Brazilian Journal of Urology. v. 28, n. 3, p. 214-220, May-june, 2002. Disponível em: <http://www.brazjurol.com.br/may_june_2002/Antonopoulos_ing_214_220.htm>. Acesso em: 12 jan. 2017.

BARBA, M.; McCANN, S.E.; SCHUNEMANN, H.J.; STRANGES, S.; FUHRMAN, B.; SABINO DE PLACIDO, S.; CARRUBA, G.; JO L FREUDENHEIM, J.O.; TREVISAN, M.; RUSSELL, M.; NOCHAJSKI, T.; MUTI, P. Lifetime total and beverage specific-alcohol intake and prostate cancer risk: a case-control study [serial online]. Nutr J, v. 3, p. 23, 2004. Disponível em: <https://nutritionj. biomedcentral.com articles/10.1186/1475-2891-3-23>. Acesso em: 13 jan. 2017.

BARRIOS, C.H. Câncer de próstata. In: MURAD, A.M.; KATS, A. (Org).

Oncologia, bases clínicas do tratamento. Rio de Janeiro: Guanabara Koogan: 1996. p. 220-227. Disponível em: <https://nutritionj.biomedcentral.com/articles /10.1186/1475-2891-3-23>. Acesso em: 10 dez. 2016. 
BONETI, R.S.; FAGUNDES, R.B. Vitamina D e câncer. Revista da AMRIGS, v. 57, n. 1, p. 71-77, Porto Alegre, 2013. Disponível em: <http://www.amrigs.com.br/ revista/57-01/artigo_revisao.pdf>. Acesso em: 15 abr. 2016.

BRASIL. Ministério da Saúde. Gabinete do Ministro. Portaria no 1.944, de 27 de agosto de 2009. Institui no âmbito do Sistema Único de Saúde (SUS), a Política Nacional de Atenção Integral à Saúde do Homem; Diário Oficial da União, Brasília, DF, 2009a. Disponível em: <http://bvsms.saude.gov.br/bvs/saudelegis/ gm/2009/prt1944_27_08_2009.html> Acesso em: 22 abril 2016.

BRASIL. Ministério da Saúde. Secretaria de Atenção à Saúde. Departamento de Ações Programáticas Estratégicas. Política Nacional de Atenção Integral à Saúde do Homem (Princípios e Diretrizes). Brasília: Ministério da Saúde, 2009b.

BRASIL. Ministério da Saúde. Secretaria de Atenção à Saúde. Departamento de Atenção Básica. Rastreamento. Brasília: Ministério da Saúde, v. 29, p. 9-73, 2010.

BRESLOW, R.A.; WEED, D.L. Review of epidemiologic studies of alcohol and prostate câncer: 1971-1996. Nutr Cancer, v. 30, n. 1, p. 1-13, 1998. Disponível em: <www.ncbi.nlm.nih.gov/pubmed/9507506>. Acesso em: 31 mar. 2017.

CASTRO, H.A.S.; IARED, W.; SHIGUEOKA, D.C.; MOURÃO, J. E.; AJZEN, S. Contribuição da densidade do PSA para predizer o câncer da próstata em pacientes com valores de PSA entre 2,6 e 10,0 ng/ml. Radiol Bras, v. 44, n. 4, p. 205-209, 2011. Disponível em: <http://www.scielo.br/pdf/rb/v44n4/v44n4a03.pdf>. Acesso em: 12 fev. 2017.

CAMBRUZZI, E.; ZETTLER, C.G.; PEGAS, K.L.; TEIXEIRA, S.L. Relação entre escore de Gleason e fatores prognósticos no adenocarcinoma acinar de próstata. J Bras Patol Med Lab, v. 46, p. 61-68, 2010. Disponível em: <http://www.scielo.br /pdf/jbpml/v46n1/v46n1a11.pdf>. Acesso em: 12 dez. 2016.

CATALONA, W.J.; SMITH, D.S.; ORNSTEIN, D.K. Prostate cancer detection in men with serum PSA concentrations of 2.6 to $4.0 \mathrm{ng} / \mathrm{mL}$ and benign prostate examination. Enhancement of specificity with free PSA measurements. JAMA, v. 277, p. 1452-61, 1977. Disponível em: <http://www.ncbi.nlm.nih.gov/pubmed/ 9145717>. Acesso em: 15 abr. 2015

COLBERG, J.W.; SMITH, D.S.; CATALONA, W.J. Prevalence and pathological extent of prostate cancer in men with prostate specific antigen levels of 2.9 to 4.0ng/ml. J Urol, v. 149, p. 507-9. 1993. Disponível em: <http://www.ncbi.nlm .nih.gov/pubmed/7679753>. Acesso em: 15 abr. 2015. 
DAMIÃO, R.; FIGUEIREDO, R.T.; DORNAS, M.C.; LIMA, D.S.; KOSCHORKE, M.A.B. Câncer de próstata. Hospital Universitário Pedro Ernesto, v. 14, supl. 1, 2015. Disponível em: <http://www.e-publicacoes.uerj.br/ojs/index.php/revistahupe/ article/view/17931/13463>. Acesso em: 26 mar. 2016.

D'AMICO, A.V.; WHITTINGTON, R.; MALKOWICZ, S.B.; SCHULTZ, D.; RENSHAW, A.D.; TOMASZEWSKI, J.E.; RICHIE, J.P.; WEIN, A. Optimizing patient selection for dose escalation techniques using the prostate-specific antigen level, biopsy gleason score, and clinical T-stage. Int. J. Radiat. Oncol. Biol. Phys., v. 45, n. 5, p. 1227-1233, 1999. Disponivel em: < http://www.redjournal.org/ article/S0360-3016(99)00303-X/references>. Acesso em: 14 jan. 2017.

DANTAS, E.L.R.; SÁ, F.H.D.L.; CARVALHO, S.M.D.F.D.; ARRUDA, A.P.; RIBEIRO, E.M.; Genética do câncer hereditário. Rev Bras Cancerol, v. 55, n.3, p. 263-269, 2009. Disponível em: < http://www.inca.gov.br/rbc/n_55/v03/pdf/67_ revisao_literatura1.pdf>. Acesso em: 03 mar. 2017.

DINI, L. I.; KOFF, W. J. Perfil do câncer de próstata no hospital de clínicas de Porto Alegre. Rev. Assoc. Med. Bras. São Paulo, v. 52, n. 1, p. 28-31, jan./fev. 2006. Disponível em: <http://www.scielo.br/scielo.php?pid=S0104-42302006 000100018\&script=sci_abstract\&tIng=pt>. Acesso em: 19 nov. 2016.

DRAISMA, G.; POSTMA, R.; SCHREODER, F.H.; KWAST, T.H. VAN DER; KONING, H.J. Gleason score, age and screening: Modeling dedifferentiation in prostate cancer. Int. J. Cancer, v. 119, p. 2366-2371, 2006. Disponível em: <http://www.ncbi.nlm.nih.gov/pubmed/16858675> Acesso em: 15 abr. 2015.

EL BAROUKI, M. P. Rastreamento do câncer de próstata em homens acima de 50 anos através do exame diagnóstico de PSA. Revista Eletrônica Gestão \& Saúde [online], 2012 v. 3, n. 2, p. 704-716, 2012. Disponível em: <https://dialnet. unirioja.es/descarga/articulo/5555768.pdf>. Acesso em: 18 jan. 2017.

FARMER, R. Prostate cancer: epidemiology and risk jactors. Trends in Urology Gynaecology \& Sexual Health. May/june, 2008. Disponível em: $<$ http://onlinelibrary.wiley.com/doi/10.1002/tre.71/abstract>. Acesso em: 13 mar. 2017.

FERNANDES, M.V.; MARTINS, J.T.; CARDELLI, A.A.A.M.; MARCON, S.S.; RIBEIRO, R.P. Epidemiological profile of men with prostare cancer attended in a teaching hospital. Cogitare Enferm, v. 19, n. 2, p. 310-317. abr/jun, 2014. Disponível em: <http://revistas.ufpr.br/cogitare/article/download/31540/22807>. Acesso em: 3 mar. 2017. 
FERNÁNDEZ, L.; GALAN Y.; GUTIÉRREZ, M.G.; PERADA, M.C; ALONSO, C.; AGUDO, A.; RIBOLI, E.; GONZÁLEZ, C. Estudio de casos y controles sobre factores de risgo de cancer de próstata. Revista Cubana Salud Pública, v. 31, n. 3, p. 174-81, 2005. Disponível em: <http://www.redalyc.org/articulo.oa?id= 21431302>. Acesso em: 12 jan. 2017.

FOSTER, C.S.; KE, Y. Steam cells in prostatic epithelia. Rev Int J Pathol, v. 78, p. 311-329, 1997.

GOMES, R.; REBELLO, L.E.F.S.; ARAÚJO, F.C.D.; NASCIMENTO, E.F.D. A prevenção do câncer de próstata: uma revisão da literatura. Ciência \& Saúde Coletiva, v. 13, n. 1, p. 235-246, 2008. Disponível em: <http://www.scielo.br/ scielo.php?script=sci_arttext\&pid=S1413-81232008000100027 >. Acesso em: 10 nov. 2016.

GONÇALVES, I.R.; PADOVANI, C.; POPIM, R.C. Caracterização epidemiológica e demográfica de homens com câncer de próstata. Ciência \& Saúde Coletiva, n. 13, v. 4, p. 1337-1342, 2008. Disponível em: <http://www.scielo.br/scielo.php?pid= S1413-81232008000400031\&script=sci_abstract\&tlng=pt>. Acesso em: 13 jan. 2017.

GONG, Z.; KRISTAL, A.R.; SCHENK, J.M.; TANGEN, C.M.; GOODMAN, P.J.; M. THOMPSON, M. Alcohol Consumption, Finasteride, and Prostate Cancer Risk. American Cancer Society, p. 3661-3669, 2009. Disponível em:

<https://www.ncbi.nlm.nih.gov/pubmed/19598210>. Acesso em: 22 jan. 2017.

HERNANDEZ, T.G.; GONZALEZ, A.V.; PEIDRO, J.P.; TORRECILLA, J.L.; FERRANDO, J.R.; CONGALEZ, L.B.; CABANERO, D.; REBOLLEDA, J.G.F.; JURADO, R.S. Feasibility of the use of PET/CT with $18 \mathrm{~F}$-colina to increase the dose intraprostaticas lesions in radiotherapy of prostate cancer treatment. III Joint Congress Spanish Societies of Medical Physics and Radiation Protection, 18-21 Jun. 2013. Caceres Spain, 2013. Disponível em: <https://inis.iaea.org/ search/search.aspx?orig_q=RN:46132606>. Acesso em: 3 mar. 2017.

HO, T.; HOWARD, L. E.; VIDAL, A. C.; GERBER, L.; MOREIRA, D.; McKEEVER, M.; ANDRIOLE, G.; CASTRO-SANTAMARIA, R.; FREEDLAND, S. J. Smoking and Risk of Low- and High-Grade Prostate Cancer: Results from the REDUCE Study. Clin Cancer Res, v. 20, n. 20, p. 5331-8, 2014.

HOFFMAN, R.M.; GILLILAND, F.D.; ELEY, J.W.; HARLAN, L.C.H.; STEPHENSON, R.A.; STANFORD, J.L.; ALBERTSON, P.C.; HAMILTON, A.S.; HUNT, W.C.; POTOSKY, A.L. Racial and ethinic diferences in advantage-stage prostate câncer: the prostate câncer outcomes study. J Natl Cancer Inst, v. 93, n. 5, p. 388-95, 7 mar. 2001. Disponível em: <https://www.ncbi.nlm.nih.gov/pubmed/ 11238701>. Acesso em: 6 abr. 2017. 
HUNCHAREK, M.; HADDOCK, K.S.; REID, R.; KUPELNICK, B. Smoking as a risk fator for prostate câncer: a meta-analysis of 24 prospective cohort studies. Am J Public Health, v. 100, n. 4, p. 693-701, April, 2010. Disponível em: <https://www.ncbi.nlm.nih.gov/pmc/articles/PMC2836346/>. Acesso em: 31 mar. 2017.

IBGE. Instituto Brasileiro de Geografia e Estatística. Cidades. 2010a. Disponível em: <http://cidades.ibge.gov.br/xtras/uf.php?lang=\&coduf=31\&search=minasgerais>. Acesso em: 13 ago. 2016.

IBGE. Instituto Brasileiro de Geografia e Estatística. Estatística. 2010b. Disponível em: <http://ibge.gov.br/home/estatistica/população/censo2010>. Acesso em: 17 ago. 2016.

INCA. Instituto Nacional do Câncer. Ministério da Saúde. Homepage (2014a). Atlas on-line de Mortalidade. Disponível em: <https://mortalidade.inca.gov.br/ MortalidadeWeb/pages/Modelo06/consultar.xhtml;jsessionid=43855FF8DE176BB 1AA6D016D6C36E86A\#panelResultado>. Acesso em: 28 set. 2014.

. O que é câncer. Ministério da Saúde. Homepage (2014b). Disponível em: <http://www2.inca.gov.br/wps/wcm/connect/cancer/site/oquee>. Acesso em: 28 set. 2014.

. Próstata. Ministério da Saúde. Homepage (2014c). Disponível em: <http://www2.inca.gov.br/wps/wcm/connect/tiposdecancer/site/home/prostata>. Acesso em: 28 set. 2014.

Ministério da Saúde. Monitoramento das ações de controle do câncer de próstata. Instituto Nacional de Câncer José Alencar Gomes da Silva, v.5, n2, ago. 2014d. Disponível em: <http://www1.inca.gov.br/inca/Arquivos/Informativo_ Deteccao_Precoce_2_agosto_2014.pdf>. Acesso em: 26 mar. 2016.

- Ministério da Saúde. Estimativa 2016a: Incidência de câncer no Brasil. Instituto Nacional de Câncer José Alencar Gomes da Silva, Rio de janeiro, 2016. Disponível em: <http://www.inca.gov.br/estimativa/2016/estimativa-2016-v11.pdf>. Acesso em: 26 mar. 2016.

. Ministério da Saúde. Tipos de câncer: Próstata. 2016b. Disponível em: <http://www2.inca.gov.br/wps/wcm/connect/tiposdecancer/site/home/prostata>. Acesso em: 26 mar. 2016.

Ministério da Saúde. Estimativas para o ano de 2016 das taxas brutas de incidência por 100 mil habitantes e do número de casos novos de câncer, em homens e mulheres, segundo a região. 2016c. Disponível em: < http://www.inca.gov.br/estimativa/2016/tbregioes_consolidado.asp>. Acesso em: 26 mar. 2016. 
ISLAMI, F.; MOREIRA, D.M.; BOFFETTA, P.; FRREDLAND, S.J. A systematic review anda meta-analysis of tobacco use and prostate cancer mortality and incidence in porspective cohort studies. Eur Urol, v. 66, n. 6, p. 1054-64, Dec. 2014. Disponivel em: <https://www.ncbi.nlm.nih.gov/pubmed/25242554>. Acesso em: 31 mar. 2017.

JAIN, S.; SAXENA, S.; KUMAR, A. Epidemiology of prostate cancer in India. Meta Gene, v. 2, p. 596-605, 2014. Disponível em: <https://www.ncbi.nlm.nih.gov/pmc/ articles/PMC4287887/>. Acesso em: 5 dez. 2016.

JEMAL, A.; SIEGEL, R.; XU, J.; WARD, E. Cancer statistics. Cancer J Clin, v. 60. p. 277-300, 2010. Disponível em: <https://www.ncbi.nlm.nih.gov/pubmed /20610543>. Acesso em: 12 jan. 2017.

JURADO, R.S.; CARVALHO, C.; ROSA, D.; COSTA, F.; GÓIS, J., ARAÚJO, A.; FRANÇA, L.; OLIVEIRA, S. Câncer de próstata: epidemiologia, fatores de risco, diagnóstico e tratamento. XVIII Encontro nacional dos grupos PET - ENAPET. Recife-PE, UFPE/UFRPE, 1 - 6 out. 2013.-

KRISTAL, A.R.; CHEN, C.; TANGEN, C.M.; GOODMAN, F.J.; ETZIONI, R.; THOMPSON, I.M. Associations of Demographic and Lifestyle Characteristics with Prostate-Specific Antigen (PSA) Concentration and Rate of PSA Increase. American Cancer Society, v. 106, n. 2, p. 320-328, 2006. Disponível em: <http://onlinelibrary. wiley.com/doi/10.1002/cncr.21603/abstract>. Acesso em: 15 abr. 2015.

KRUMHOLTZ, J.S.; CARVALHAL, G.F.; RAMOS, C.G.; SMITH, D.S.; THORSON, P.; YAN, Y.; HUMPHREY, P.A.; ROEHL, K.A.; CATALONA, W.J. Prostate specific antigen cutoff of $2.6 \mathrm{ng} / \mathrm{mL}$ for prostate cancer screening is associated with favorable pathologic tumor features. Urology, v. 60, p. 469-74, 2002. Disponível em: <http://www.ncbi.nlm.nih.gov/pubmed/12350486>. Acesso em: 15 abr. 2015.

KRYVENKO, O.N.; EPSTEIN, J.I. Prostate Cancer Grading: A Decade After the 2005 Modified Gleason Grading System. Arch Pathol Lab Med, v. 140, p. 11401152, 2016. Disponível em: <http://www.archivesofpathology.org/ doi/pdf/ 10.5858/arpa.2015-0487-SA?code= coap-site >. Acesso em: 12 mar. 2017.

LIMA, C.A.; SILVA, A.M.; KUWANOC, A.Y.; Margareth Rose Uchôa RANGELA, M.R.U.; MACEDO-LIMA, M. Trends in prostate cancer incidence and mortality in a mid-sized Northeastern Brazilian city. Revista da Associação Médica Brasileira, v. 59, n. 1, p. 15-20, 2013. Disponível em: <http://www.sciencedirect.com/science/ article/pii/S2255482313704247> Acesso em: 02 maio 2015. 
MADERSBACHER, S.; ALCARAZ, A.; EMBERTON, M.; HAMMERER, P. PONHOLZER, A.; SCHRöDER, F. H.; TUBARO, A. The influence of family history on prostate cancer risk: implications for clinical management. BJU International, Philadelphia, v. 107, n. 5, p. 716-731, 2010. Disponível em: <https://www.ncbi.nlm. nih.gov/pubmed/21166744>. Acesso em: 12 jan. 2017.

MARTIN, E.N.; CHEN, M-H.; BEARD, M.J.L.; KANTOFF, P.W.; D'AMICO, A.V. Biopy Gleason score and the duration of testosterone suppression among men treated with external beam radiation and 6 months of combined androgen blockade. BJU International, v. 110, p. 1252-1256, 2012.

MARTINS, A.C.P.; REIS, R.B.; SUAID, H.J.; MACIEL, L.M.; ZANINI, A.J.C.; FALCONI, R.A.R. Screening for carcinoma of the prostate in volunteers. International Braz. J. Urol., Rio de Janeiro, v. 26, n. 5, p. 516-522, 2000. Disponível em: < http://www.brazjurol.com.br/27_2000/pdf/Pereira_Martins_516 _522.pdf>. Acesso em: 12 dez. 2016.

McANINCH, J.; LUE, T.F. Urologia geral de Smith e Tanagho. 18. ed. Porto Alegre: AMGH, 2014. 768p.

MIGOWSKI, A.; SILVA, G. A. Sobrevida e fatores prognósticos de pacientes com câncer de próstata clinicamente localizado. Rev. Saúde Pública, v. 44. n. 2. p. 344-352, 2010. Disponível em: <http://www.scielo.br/pdf/rsp/v44n2/16.pdf>. Acesso em: 25 nov. 2016.

MOREIRA, M.V.S.; SOUZA, V.C.; LIMA, B.G.C.; OLIVEIRA, E.L.; DE MOURA, C.A.G.G.; DE MOURA, C.G.G.; CRUZ, C.M.S. Comparação do escore de Gleason da biópsia prostática com o da peça cirúrgica em pacientes com câncer de próstata. Revista Brasileira de Clínica Médica. v. 10, n. 5, p. 367-71, São Paulo, set-out. 2012. Disponível em: <http://files.bvs.br/upload/S/16791010/2012/v10n5/a3148.pdf>. Acesso em: 12 jan. 2017.

MOUL, J.W.; SESTERHENN, I.A.; CONNELLY, R.R.; DOUGLAS, T.; SRIVASTAVA, S.; MOSTOFI, F.K.; McLEOD, D.G. Prostatic specific antigen values at the time of prostate cancer diagnosis in African-americam mem. JAMA, v. 25, p. 1277-1281, 1995. Disponível em: <https://www.ncbi.nlm.nih.gov/pubmed/ 7563532>. Acesso em: 12 mar. 2017.

NARDI, A.C.; POMPEO, A.C.L.; FARIA, E.F.; GUIMARÃES, G.C.; CALIXTO, J.R.; DA PONTE, J.R.T.; NOGUEIRA, L.; LEAL, M.C.O.; BERGER, M.; ANDRADE, N.;

BERNARDO, W.M. SBU. Sociedade Brasileira de Urologia. Câncer de Próstata: diagnóstico. s.d. Disponível em: <http://www.sbu.org.br/pdf/diretrizes/novo/ cancer_de_prostata_diagnostico.pdf>. Acesso em: 25 set. 2014. 
NARDI, A.C.; REIS, R.B.; ZEQUI, S. de C.; NARDOZZA, A. JR. Comparison of the Epidemiologic Features and Patterns of Initial Care for Prostate Cancer between Public and Private Institutions: A Survey by the Brazilian Society of Urology. Int Braz J Urol., v. 38. p. 155-166, 2012. Disponível em:

<https://www.ncbi.nlm.nih.gov/pubmed/22555039>. Acesso em: 12 jan. 2017.

NASSIF, E.A.; ACBC-PR; FILHO, R.A.; DE PAULA, G.X.; TAGUCHI, W.S.; POZZOBON, P.J. Perfil epidemiológico e fatores prognósticos no tratamento cirúrgico do adenocarcinoma de próstata clinicamente localizado. Rev. Col. Bras. Cir, v. 36, n. 4, p. 327-331, 2009. Disponível em: <http://www.scielo.br/pdf/rcbc/ v36n4/a10v36n4.pdf>. Acesso em: 7 dez. 2016.

NOVAES, P.; MOTTA, R.T.; LUNDGREN, M.S.F.S. Tratamento de câncer da próstata com radioterapia de intensidade modulada. 2013. 21 p. DiretrizSociedade Brasileira de Radioterapia - SBRT. Disponível em: <http://www.sbradioterapia.com.br/pdfs/tratamento-do-cancer-de-prostata-comradioterapia-de-intensidade-modulada.pdf> Acesso em: 14 de fev. 2016.

ORTIZ, V. Câncer da próstata: vigilância ativa. Disponível em: <http://www.moreirajr.com.br/revistas.asp?fase=r003\&id_materia=4176>. Acesso em: 14 de fev. 2016.

PARKIN, D.M.; BRAY, F.I.; DEVESA, S.S. Cancer burden in the year 2000. The global picture. Eur J Cancer, v. 37, n. 8, p. 4-66, 2001. Disponível em:

<https://www.ncbi.nlm.nih.gov/pubmed/11602373>. Acesso em: 4 mar. 2017.

PENAFORTE, A.C.C.; MOURA, H. dos S.S.; GOIS, L.P.B.L.; ALCANTARA, D.F.; ALMEIDA NETO, A.A. Estudo epidemiológico dos casos diagnosticados de câncer de próstata na região do submédio São Francisco no período de 2005 a 2009. Disponível em: <http://apps.cofen.gov.br/cbcenf/sistemainscricoes/ arquivosTrabalhos//35081.E10.T7921.D6AP.pdf>. Acesso em: 10 set. 2015.

PIANTINO, C.B. MOREIRA, R.C.; PIMENTA, R.C.A.; SILVA, T.A.; ÁVILA, D.; SANTOS, M. Perfil clínico-epidemiológico do câncer de próstata em um hospital de referência em Passos, Minas Gerais. Ciência Et. Praxis, v. 7. n. 14. p. 35-38, 2014.

PUTNAM, S.D.; CERHAN, J.R.; PARKER, A.S.; BIANCHI, G.D.; WALLACE, R.B.; CANTOR, K.P.; LYNCH, C.F. Lifestyle and anthropometric risk factors for prostate câncer in a cohort of lowa men. Ann Epidemiol, v. 10, n. 6, p. 361-369, Aug. 2000. Disponível em: <https://www.ncbi.nlm.nih.gov/punmed/10964002>. Acesso em: 31 mar. 2017.

RAJINIKANTH, A.; MANOHARAN, M.; SOLOWAY, C.T.; CIVANTOS, F.J.; SOLOWAY, M.S. Trends in Gleason score: concordance between biopsy and prostatectomy over 15 years. Urology, v. 72, p. 177-182, 2008. 
RANDAZZO, M.; MULLER, A.; CARLSSON, S.; EBERLI, D.; HUBER, A.; GROBHOLZ, R.; MANKA, L.; MORTEZAVI, A.; SULSER, T.; RECKER, F.; KWIATKOWSKI, M. A positive family history as a risk factor for prostate cancer in a population-based study with organized prostate-specific antigen screening: results of the Swiss European randomized study of creening for prostate cancer (AERSPC Aarau). BJU Int, v. 117, n. 4, p. 576-83. Apr. 2016. Disponível em: <https://www.ncbi.nlm.nih.gov/pubmed/26332304>. Acesso em: 6 abr. 2017.

RAPITI, E.; SCHAFFAR, R.; ISELIN, C.; BOUCHARD, C. Importance and determinants of Gleason score undergrading on biopsy sample of prostate cancer in a population-based study. BMC Urology, v.13, p.1-6, 2013. Disponível em: $<$ https://www.researchgate.net/publication/236194625_Importance_and_determin ants_of_Gleason_score_undergrading_on_biopsy_sample_of_prostate_cancer_in _a_population-based_study>. Acesso em: 12 jan. 2017.

RIBEIRO, P.V.F.; SILVA, R.R.; SANTOS, K.K.D.A.T.; LOUREIRO, F.H.F.; COSTA, P.F.A.F.; URUÇU, L.M.; CARLOS, A.B.S.; MACHADO, T.M.; VALDEZ, E.F.M.G.; AMARAL, V.B. Análise clínica e epidemiológica de 348 casos de adenocarcinoma prostático atendidos em um centro oncológico de referência no Maranhão, Brasil, Revista Brasileira de Cancerologia, v. 59, n. 4, p.513-521, 2013. Disponível em: <http://www.inca.gov.br/rbc/n_59/v04/pdf/04- artigo-analiseclinica-e-epidemiologica-de-348-casos-adenocarcinoma-prostatico-atendidos-emum-centro-oncologico-referencia-no-maranhao-brasil.pdf>. Acesso em: 18 jan. 2017.

RODRIGUES, R.; SALES, C.A. Aspectos epidemiológicos e diagnósticos do carcinoma prostático. Revista Saúde e Pesquisa, v. 6, n. 1, p. 131-140, 2013. Disponível em: <http://periodicos.unicesumar.edu.br/index.php/saudpesq/article/ viewFile/2620/1855>. Acesso em: 03 mar. 2017.

ROMERO, F. R. Fatores de risco para câncer de próstata em uma amostra da população de Curitiba, PR. 2012. Tese (Doutorado em Clínica Cirúrgica) Universidade Federal do Paraná, Curitiba, Paraná. 233p. Disponível em: $<$ http://acervodigital.ufpr.br/ > Acesso em: 16 maio 2016.

ROUS, S.N. Guia completo da próstata: informação médica sobre sintomas e tratamento. São Paulo: Gaia, 2010.

RUSSO, A.L.; MING-HUI, C.; AIZER, A.A.; HATTANGADI, J.A.; D'AMICO, A.V. Advancing age within established Gleason score categories and the risk of prostate cancer-specific mortality (PCSM). Bju International, v. 110, p. 973-979, 2012. Disponível em: <https://www.ncbi.nlm.nih.gov/labs/articles/22954029/>. Acesso em: 4 mar. 2017. 
SAARIMÄKI, L.; TAMMELA, T.L.; MÄÄTTÄNEN, L.; TAARI, K.; KUJALA, P.M.; RAITANEN, J.; AUVINEN, A. Family history in the Finninsh Prostate Cancer Screening Trial. Int J Cancer, v. 136, n. 9, p. 2172-7, 01 May, 2015. Disponível em: <https://www.ncbi.nlm.nih.gov/pubmed/25274038. Acesso em: 6 abr. 2017.

SAN FRANCISCO, I.F.; DEWOLF, W.C.; ROSEN, S.; UPTON, M.; OLUMI, A.F. Extended prostate needle biopsy improves concordance of Gleason grading between prostate needle biopsy and radical prostatectomy. The Journal of Urology, Boston, v. 169. p. 136-40, 2003. Disponível em: <https://www.ncbi.nlm.nih.gov/pubmed/12478121>. Acesso em: 20 fev. 2017.

SAWADA, N.; INOUE, M.; IWASAKI, S.; YAMAJI, T.; SHIMAZU, T.; TSUGANE, S. Alcohol and smoking and subsequent risk of prostate cancer in Japanese men: The Japan Public Health Center-based prospective study. Int J Cancer, v. 134, n. 4, p. 971-978, 15 Feb. 2014. Disponível em: <https://www.ncbi.nlm.nih.gov/ pubmed/23929133>. Acesso em: 24 mar. 2017.

SBU. Sociedade Brasileira de Urologia. Câncer de próstata localizado:

Tratamento. Projeto Diretrizes. Associação Médica Brasileira (AMB) Conselho Federal de Medicina. São Paulo, p. 1-13, 2006. Disponível em:

$<$ https://diretrizes.amb.org.br/_BibliotecaAntiga/cancer-de-prostata-localizadotratamento.pdf>. Acesso em: 03 mar. 2017.

SESSO, H.D.; PAFFENBARGER, R.S.; LEE, I.M. Alcohol consumption and risk of prostate cancer: the Harvard alumni health stydy. Int J Epidemiol, v. 30, n. 4, p. 749-55 Aug. 2001. Disponivel em: <https://www.ncbi.nlm.nih.gov/pubmed/ 11511598>. Acesso em: 31 mar. 2017.

SHAH, N.; IOFFE, V. Frequency of Gleason score 7 to 10 in 5100 elderly prostate câncer patientes. Rev Urol, v. 18, n. 4, p. 181-187, 2016. Disponível em:

<https://www.ncbi.nlm.nih.gov/pmc/articles/PMC5260947/>. Acesso em: 31 mar. 2017.

SIDDIQUI, S. A.; SENGUPTA, S.; SLEZAK, J.M.; BERGSTRALH, E.J.; ZINCKE, H.; BLUTE, M.L. Impact of familial and hereditary prostate cancer on cancer specific survival after radical retropubic prostatectomy. Journal of Urology, v. 176, n. 3, p. 1118-1121, 2006. Disponível em: <https://www.ncbi.nlm.nih.gov/ pubmed/16890705>. Acesso em: 19 nov. 2016.

SILVA, S.E.D.; ALMEIDA, M.R.; CORRÊA, A.C.A.; Jhon Müller N. MONTEIRO, J.M.N.; GONÇALVES, P.J.C.; CARNEIRO, R.B.; GOMES, S.C.A.; BRAVO, T.B.; AMARAL, T.L.; VASCONCELOS, E.V.; CUNHA, N.F.; SANTOS, P.A.; Jeferson Araújo dos SANTOS, J.A. Câncer - uma doença psicossocial: câncer no homem e a herança da cultura machista. Gestão e Saúde, Revista Eletrônica Gestão \& Saúde, v. 6, n. 1, p. 606-616, 2015. Disponível em: <http://periodicos.unb.br/ index.php/rgs/article/view/13756/9690 >. Acesso em: 10 fev. 2016. 
SOUZA, A. R. A.; ALMEIDA, S. S.; OLIVEIRA, D.C. Análise estatística do câncer de próstata por meio da regressão logística. Rev. Bras. Biom, v. 31. n. 3. p. 441448, 2013. Disponível em: <http://jaguar.fcav.unesp.br/RME/fasciculos/ v31/v31_n3/A8_Almir_Silvia_Diana.pdf>. Acesso em: 10 nov. 2016.

SROUGI, M.; RIBEIRO, L.A.; PIOVESAN, A.C.; COLOMBO, J.R.; NESRALLAH, A. Doenças da próstata. Rev Med. São Paulo, v. 87, n. 3, p. 166-177, 2008.

TELANG, J.M.; LANE, B.R.; CHER, M.L.; MILLER, D.C.; DUPREE, J.M. Prostate cancer, family history, and eligibility for active surveillance: A systematic review of the literature. BJU Int. 29 mar. 2017. Disponível em: <https://www.ncbi.nlm.nih. gov/pubmed/28371016>. Acesso em: 20 abr. 2017.

THICKMAN, D.; SPEERS, W.C.; PHILPOTT, P.J.; SHAPIRO, H. Effect of the number of core biopsies of the prostate on predicting Gleason score of prostate cancer. J Urol, v. 156, p. 110-113, 1996.

THOMPSON, I.M.; ANKERST, D.P.; CHI, C.; GOODMAN,P.J.; TANGEN, C.M.; LUCIA, M.S.; FENG, Z.; PARNES, H.L.; COLTMAN, C.A. Assessing prostate cancer risk: results from the prostate cancer prevention trial. $J$ Natl Cancer Inst, v. 98, p. 529-34, 2006. Disponível em: <https://www.ncbi.nlm.nih. gov/pubmed/16622122>. Acesso em: 18 jan. 2017.

US DEPARTMENT OF HEALTH AND HUMAN SERVICES. The Health Consequences of Smoking: A Report of the Surgeon General. Atlanta, GA: US Department of Health and Human Services, 2004.

WALSH, P.C.; RETIK, A.B.; STAMEY, T.A. Campbell's urology, 7th ed. Philadelphia: WB Saunders, 1997, p. 2492-2493.

WESTOVER, K.; CHEN, M.H.; MOUL, J.; ROBERTSON, C.; POLASCIK, T.; DOSORETZ, D.; KATIN, M.; SALENIUS, S.; D'AMICO, A.V. Radical prostatectomy vs radiation therapy and androgen-suppression therapy in high-risk prostate. BJU international, v.110, p.1116- 122, 2012. Disponível em: <https://www.ncbi.nlm. nih.gov/pubmed/22540922>. Acesso em: 13 jan. 2017.

WU, V.J.; PANG, D.; TANG, W.W.; ZHANG, X.; LI, L.; ZONGBING YOU, Z. Obesity, age, ethnicity, and clinical features of prostate cancer patients. Am J Clin Exp Urol, v. 5, n. 1, p. 1-9, 2017. Disponível em: <https://www.ncbi.nlm.nih.gov/ pmc/articles/ PMC5344988/>. Acesso em: 10 abr. 2017.

ZACCHI, S.R.; AMORIM, M.H.C.; SOUZA, M.A.C.; MIOTTO, M.H.M.B.; ZANDONADE, E. Associação de variáveis sociodemográficas e clínicas com o estadiamento inicial em homens com câncer de próstata. Cad. Saúde Colet, v. 22. p. 93-100, 2014. Disponível em: <http://www.scielo.br/pdf/cadsc/v22n1/1414462X-cadsc-22-01-00093.pdf>. Acesso em: 20 fev. 2017. 
ZU, K.; GIOVANNUCCI, E. Smoking and aggressive prostate cancer: a review of the epidemiologic evidence. Cancer Causes Control, v. 20, n. 10, p. 1799-1810, 2009. Disponível em: <https://www.ncbi.nlm.nih.gov/pubmed/19562492>. Acesso em: 31 mar. 2017. 